\title{
Certification Framework Based on Effective Trapping for Geologic Carbon Sequestration
}

\author{
Curtis M. Oldenburg ${ }^{1}$, Steven L. Bryant ${ }^{2}$, and Jean-Philippe Nicot ${ }^{3}$ \\ ${ }^{1}$ Earth Sciences Division, 90-1116, \\ Lawrence Berkeley National Laboratory, 1 Cyclotron Rd. \\ Berkeley CA 94720 \\ cmoldenburg@lbl.gov \\ ${ }^{2}$ Center for Petroleum and Geosciences Engineering, \\ University of Texas, Austin, \\ 1 University Station C0300 \\ Austin, TX 78712-0228 \\ Steven_bryant@mail.utexas.edu \\ ${ }^{3}$ Bureau of Economic Geology, \\ Jackson School of Geosciences, \\ University of Texas, \\ University Station, Box X \\ Austin, Texas 78713-8924 \\ ip.nicot@beg.utexas.edu
}

November 9, 2008

Revised February 2, 2009

Corresponding author:

Curt Oldenburg, 510-486-7419, fax: 510-486-5686, cmoldenburg@lbl.gov

Key Words:

Geologic carbon sequestration, leakage risk, risk assessment 


\section{Abstract}

We have developed a certification framework (CF) for certifying the safety and effectiveness of geologic carbon sequestration (GCS) sites. Safety and effectiveness are achieved if $\mathrm{CO}_{2}$ and displaced brine have no significant impact on humans, other living things, resources, or the environment. In the $\mathrm{CF}$, we relate effective trapping to $\mathrm{CO}_{2}$ leakage risk which takes into account both the impact and probability of leakage. We achieve simplicity in the CF by using (1) wells and faults as the potential leakage pathways, (2) compartments to represent environmental resources that may be impacted by leakage, (3) $\mathrm{CO}_{2}$ fluxes and concentrations in the compartments as proxies for impact to vulnerable entities, (4) broad ranges of storage formation properties to generate a catalog of simulated plume movements, and (5) probabilities of intersection of the $\mathrm{CO}_{2}$ plume with the conduits and compartments. We demonstrate the approach to a hypothetical GCS site in a Texas Gulf Coast saline formation. Through its generality and flexibility, the CF can contribute to the assessment of risk of $\mathrm{CO}_{2}$ and brine leakage as part of the certification process for licensing and permitting of GCS sites around the world regardless of the specific regulations in place in any given country. 


\section{Introduction}

Accelerating emissions of carbon dioxide $\left(\mathrm{CO}_{2}\right)$ from the burning of fossil fuels (Raupach, 2007) and associated impacts on atmospheric $\mathrm{CO}_{2}$ concentrations and climate change are motivating an urgent search for ways to decrease $\mathrm{CO}_{2}$ emissions. With no single approach apparent on the horizon to solve this growing global energy and environmental challenge, a combination of approaches including improvements in energy efficiency, conservation, fuel-switching, growth in renewables, and carbon sequestration appears necessary (Pacala and Socolow, 2004). As an integral part of this portfolio of solutions, geologic carbon sequestration (GCS) is being evaluated and tested for its feasibility to reduce net $\mathrm{CO}_{2}$ emissions from point sources such as power plants, cement plants, and oil refineries (IPCC, 2005). At the same time, national and state governments are working to develop regulations to ensure that GCS does not negatively impact valuable resources and the environment.

The dual objectives of encouraging GCS as one of several essential climate-change mitigation strategies and protecting the environment from unintended $\mathrm{CO}_{2}$ injection-related impacts (e.g., upward migration and seepage of $\mathrm{CO}_{2}$ to the atmosphere, or intrusion of displaced brine into underground sources of drinking water (USDW)) have motivated us to develop a novel and practical risk-based framework for certifying that the leakage risk of a potential GCS site is below agreedupon thresholds. Our approach goes beyond the scope of regulations of deep underground injection permitted by the U.S. Environmental Protection Agency (EPA) which protect USDW, to consider risks to a broader set of resources and environmental assets. The approach we developed, known as the Certification Framework (CF), proposes a standardized way for project proponents, regulators, and the public to analyze and understand risks and uncertainties of GCS in a simple and transparent 
way. The CF considers both physical and chemical impacts as well as loss of emission-reduction credits due to $\mathrm{CO}_{2}$ leakage. The $\mathrm{CF}$ uses physically grounded models for the movement of injected $\mathrm{CO}_{2}$ and brine. In our current implementation the models are deliberately simple; more sophisticated models can be readily incorporated. The models are also general and require input data that describe the geologic section containing the storage formation for each site. Through its generality, the $\mathrm{CF}$ endeavors to contribute to the assessment of risk of $\mathrm{CO}_{2}$ and brine leakage as part

of the certification process for licensing and permitting of GCS sites around the world regardless of the specific regulations in place in any given country.

\section{Background}

\section{Motivation and Purpose}

Numerous examples of underground injection processes are being carried out in the U.S. and around the world (e.g., Benson et al., 2002; Wilson et al., 2003; Bachu and Gunter, 2004). These include groundwater recharge, natural gas storage, solution mining, hazardous liquid and gas waste disposal, and various injections for enhancing oil production, among others. Because there are hazards associated with injecting fluids into the subsurface, existing underground injections are variously permitted by national or regional government agencies (Wilson et al., 2003). For example, in the U.S., either the Environmental Protection Agency (USEPA) or an individual state regulates underground injection (depending on whether the state has primacy) in a program known as the Underground Injection Control (UIC) program (USEPA, 2001). The UIC program is authorized by the Safe Drinking Water Act, and as such is designed to protect USDW. While there have been cases of contamination involving permitted underground injection (e.g., Paul et al., 1997), in general 
the UIC program and its permitting process address the possible modes of failure and decrease the risk associated with injection sufficiently to enable safe and effective liquid and gas injection.

In order to reduce significantly annual U.S. fossil-fuel-derived $\mathrm{CO}_{2}$ emissions of $\sim 2.4 \mathrm{Gt}$ from power generation, and $\sim 0.9$ Gt from U.S. industrial point sources (USEPA, 2007), enormous volumes of $\mathrm{CO}_{2}$ need to be injected for GCS. We compare in Table 1 the nominal GCS volume to the largest existing injection process in the U.S., namely re-injection of produced water at oil fields (oil and water are produced on average at a ratio of approximately 1:7 by volume (Veil, 2007)). If we consider only the U.S. point-source $\mathrm{CO}_{2}$ emissions as potentially available for GCS, we see that the U.S. oil industry currently injects a similar volume of waste water into comparable geologic formations.

Although the injection volumes are similar, the requirements of existing underground injection operations that mostly involve waste water differ substantially from the needs of GCS. One difference is that oil-field water injection is most commonly re-injection into reservoirs from which water and hydrocarbons were produced, resulting in zero or negative net injection into the reservoirs. In the case of GCS in saline formations under current injection scenarios, all of the injected $\mathrm{CO}_{2}$ is new fluid that must be accommodated by displacement or compression of native fluids, and/or compression or upward displacement of the formation. Another difference is that GCS involves the storage of a buoyant fluid. Under typical storage conditions, $\mathrm{CO}_{2}$ is in a supercritical form that is gas-like in terms of viscosity, and though liquid-like in density, supercritical $\mathrm{CO}_{2}$ is less dense than surrounding brine. The resulting buoyancy that tends to drive $\mathrm{CO}_{2}$ upwards is not present in typical 
current UIC-regulated liquid injection processes. These differences prevent the inclusion of $\mathrm{CO}_{2}$ injection for GCS directly into one of the existing classes of wells in the UIC program.

As the above discussion suggests, GCS entails the possibility of $\mathrm{CO}_{2}$ or brine migration away from the storage region with potential impacts to resources such as USDW and to the near-surface environment, not to mention loss of effectiveness for $\mathrm{CO}_{2}$ emissions reduction. Before large investments are made in capture and/or combustion technology to move ahead with large-scale deployment of GCS, it is critically important that methods are developed to ensure the safety of GCS and its effectiveness as a climate change mitigation strategy. These methods include a range of monitoring, mitigation, and verification (MMV) technologies for the injection and post injection periods (e.g., Benson and Myer, 2002). Furthermore, regulatory frameworks must be developed that are compatible with monitoring technology and subsurface data availability so that the regulations will (1) ensure safety and effectiveness, and (2) not hinder implementation of GCS by being unnecessarily expensive or impractical. The purpose of this paper is to present a practical and logical risk assessment approach called the Certification Framework (CF) along with a case study carried out to demonstrate the CF approach.

\section{Prior Work on GCS Risk Assessment}

At least two main applications of risk assessment are critical for the nascent GCS industry. The first is the assessments that are carried out to select promising sites from a number of candidate sites. This we call screening and ranking (e.g., Bowden and Rigg, 2004; Oldenburg, 2008). The second is the evaluation and potential certification of particular sites as safe and effective GCS sites. Despite the fact that the boundary between these two objectives may not always be sharp, the CF is aimed at certification of a single site assuming a sufficient amount of site characterization data are available. 
There is a growing body of work in risk assessment in the areas of GCS screening and ranking and single-site certification. In the area of screening and ranking, two approaches have been described in the literature. Bowden and Rigg (2004) invoke a quantitative probabilistic approach that involves risk measures applied to key performance indicators. This approach uses the RISQUE method which involves assembling an expert panel to develop and rank potential scenarios and events. The second approach (Oldenburg, 2008) is a spreadsheet-based approach that focuses on near-surface risk of $\mathrm{CO}_{2}$ leakage called the Screening and Ranking Framework (SRF). The SRF was designed to require minimal site characterization data and provide a simple and uniform way to rank several sites based on expected performance and the certainty of the information available. The SRF approach is too qualitative to certify sites for which more site characterization data and associated modeling are needed. A third approach under development by the U.S. EPA is the Vulnerability Evaluation Framework (USEPA, 2008) useful as guiding the development of regulations, for educating stakeholders about potential risks, and for delineating regions with better or worse potential for safe and effective GCS.

For assessing individual sites, several approaches have been developed or adapted from other applications among which are the Features, Events, and Processes (FEP) scenario approach (e.g., Savage et al., 2004; Wildenborg et al., 2004; Stenhouse et al., 2005), Probabilistic Risk Assessment (PRA) (e.g., Rish 2005), and system modeling approaches (e.g., $\mathrm{CO}_{2}$-PENS (Stauffer et al., 2009)). The FEP approach involves the generation of a comprehensive list of FEPs that are codified in a database. The user can rank the importance or relevance of given FEPs and associated scenarios for performance failures, such as excessive leakage and seepage. In the PRA approach of Rish (2005), 
developed for UIC Class I hazardous waste injection wells, probabilities of events and distributions of formation and well properties are used as input for probabilistic calculations of the likelihood of various detrimental events. In the next phase of the assessment, the consequences of a scenario or of an event are expressed in terms of impact of long-term high concentrations of $\mathrm{CO}_{2}$ at key receptors. The consequences are evaluated by modeling and simulation. The product of this probability and the consequence estimate from the simulation enables the risk to be calculated. The system modeling approach (e.g., $\mathrm{CO}_{2}$ PENS, Stauffer et al., 2009) takes a much broader view and analyzes the entire system from the point of capture of $\mathrm{CO}_{2}$ from flue gas, through transportation by pipeline, to injection and trapping in the reservoir and includes economic aspects. The system modeling approach is designed to use probabilistic methods for modeling uncertainty.

For evaluation of a single GCS site, the FEP and PRA approaches are generally applicable, however both have drawbacks. While comprehensive, the FEP process involves analyzing hundreds of FEPs for each site. Some researchers argue that most GCS sites will have only a handful of relevant vulnerabilities that dominate the risk (approach taken by us with the CF), and that these are quite well known and may not require reference to the FEP database or expert elicitation. On the other hand, there are researchers who feel that a FEP analysis can be useful not only for the initial screening but also as a tool to audit other approaches. As for the PRA, obtaining accurate distributions of properties such as permeability for quantitative risk analysis is expensive at best, and impossible at worst given the difficulty of measurement and known scale effects (e.g., of permeability, see Clauser, 1992). Furthermore, while the stochastic modeling required in the PRA may be practical for single well-failure calculations, it is prohibitive for coupled flow and transport simulations and the typical lack of data available to constrain properties of GCS systems. The $\mathrm{CO}_{2-}$ 
PENS system modeling approach is general, comprehensive, and potentially very powerful. However, along with the capturing of interactions between the processes of capture, transportation, injection, migration and/or leakage, and monitoring in an environment of uncertainty comes complexity and broad data needs.

What is needed is a simple, transparent, and accepted framework for evaluating the fundamental $\mathrm{CO}_{2}$ and brine leakage risks of GCS sites. We consider the surface operations associated with GCS (capture, compression, transportation) to be sufficiently well known that existing risk frameworks can be applied to those operations. Through this assumption, we focus the CF solely on the geologic storage part of GCS and specifically exclude consideration of surface operations.

\section{The CF Approach}

\section{Rationale}

The CF approach is intended to be simple, but not too simple, and transparent in terms of what methods are being applied. Through its simplicity and transparency, we aim to have the CF accepted by a wide variety of users, and we aim to make the CF useful around the world under various different regulatory systems.

\section{GCS Performance Objective}

The basic objective of any GCS operation is to be safe and effective. In this context, the word "safe" means that impacts to humans and other living things, the environment, and other resources are acceptably low over both short and long time periods. The word "effective" means that the site will

contain indefinitely the vast majority of injected $\mathrm{CO}_{2}$ (Hepple and Benson, 2002). The basic goal of 
the CF is to evaluate the degree to which a GCS site is expected to be safe and effective in a riskassessment context. We do this by simplifying the system into a tractable and logical form amenable to modeling and analysis. We aim the CF for now at GCS in sedimentary basins and assume that these sites share common concerns such as the presence of wells and faults as potential leakage pathways.

\section{Effective trapping}

While UIC regulations address migration of injectate to USDW and the need to prevent such migration (the so-called non-migration requirement), we use instead the concept of "effective trapping” in the CF. This concept is broader than non-migration. It is intended to recognize the fact that migration of injected $\mathrm{CO}_{2}$ can significantly increase the amount stored in secure forms (e.g., dissolved in brine, trapped as a residual phase) (IPCC, 2005). The concept of effective trapping also acknowledges that enormous volumes of $\mathrm{CO}_{2}$ will be injected into the Earth's crust, which is not a leak-proof container. If small amounts of injected $\mathrm{CO}_{2}$ escape to the atmosphere, the net mitigation of $\mathrm{CO}_{2}$ emissions is still substantial. As long as the escaping $\mathrm{CO}_{2}$ has not harmed other resources, the only practical consequence would be the operator's forfeit of credits for the escaped $\mathrm{CO}_{2}$ and the effect on warming the atmosphere. Of course, harmful leakage of $\mathrm{CO}_{2}$ (or brine) into USDW, into other resources, or even out of the ground is also possible. The goal of building the CF upon the effective trapping concept is to distinguish benign from harmful migration so that the risk assessment can focus on the likelihood of the latter. Well-designed storage projects in well-chosen sites will have acceptably small likelihood and/or impact of harmful migration as calculated by the CF. 


\section{Terminology}

The CF approach uses a precise terminology. Before we can talk about leakage of $\mathrm{CO}_{2}$, we need to define what leakage is. To this end, we establish the following definitions:

- Effective Trapping is the proposed overarching requirement for safety and effectiveness.

- Storage Region is the three-dimensional volume of the subsurface intended to contain injected $\mathrm{CO}_{2}$.

- Leakage is migration across the boundary of the Storage Region.

- Compartment is a vulnerable entity or a collection of vulnerable entities (e.g., potable groundwater aquifer or aquifers).

- Impact is a consequence to a compartment, with severity evaluated by proxy concentrations or fluxes.

- Risk is the product of the probability of an impact occurring and the consequences of that impact.

- $\mathrm{CO}_{2}$ Leakage Risk (CLR) is the risk to compartments arising from $\mathrm{CO}_{2}$ migration.

- Effective Trapping is achieved if $\mathrm{CO}_{2}$ Leakage Risk is below agreed-upon thresholds.

Making use of this terminology, the purpose of the $\mathrm{CF}$ is to evaluate the $\mathrm{CO}_{2}$ Leakage Risk (CLR) for each compartment to determine whether the Effective Trapping threshold will be met for a given GCS site. Given the large amounts of brine that will be displaced by injected $\mathrm{CO}_{2}$, we further define the brine leakage risk (BLR) as the probability that negative impacts will occur to compartments due to brine migration. For the sake of simplicity, we focus on CLR in this paper, but the extension to consider also BLR is fairly straightforward. 


\section{Wells and Faults are the Conduits}

Once leakage is defined as above, we assume in the CF that wells and faults are the only potential leakage conduits. This assumption is made to simplify the analysis and is predicated on the idea that GCS sites will be well chosen so as to avoid sites with potentially discontinuous cap-rock seals, or with poorly constrained structural closure. Under this assumption, the injected $\mathrm{CO}_{2}$ and the associated over-pressured brine comprise the source of fluid that can potentially leak upward through the conduits.

\section{Impacts Occur to Compartments}

The consequences of upward leakage of $\mathrm{CO}_{2}$ or brine are impacts to compartments, which the CF uses as collections of related vulnerable entities. For example, underground sources of drinking water (USDW), taken collectively at a site, form a single compartment. In the CF, we define five compartments in which impacts will be evaluated.

- $\quad$ ECA $=$ Emission Credits and Atmosphere

- $\quad \mathrm{HS}=$ Health and Safety

- $\quad$ NSE = Near-Surface Environment

- $\mathrm{USDW}=$ Underground Source of Drinking Water

- $\quad$ HMR $=$ Hydrocarbon and Mineral Resources

The compartments have general locations within the system but are abstract in the sense that they are collections and may include disconnected pieces. For example, there may be multiple zones of USDW separated by HMR-bearing layers, and yet the CF would utilize only one USDW compartment. Similarly, the HS compartment is abstract in that safety could refer to both a resident 
in a home or a worker in an office building; in both cases, the people are part of a single HS compartment even though they may be in different parts of town at different times of day. The ECA compartment is even more abstract in that emission credits are not physical entities.

We present in Figure 1a a cross section of a generic GCS site showing a deep structure potentially suitable for use in sequestering $\mathrm{CO}_{2}$, sealing formations, an oil-bearing formation, faults, wells, USDW, vegetation, and a residence with water well. This conceptualization of common elements of a GCS system is further abstracted to consist of the source, conduits, and compartments of Figure 1b. In summary, the CF simplifies the GCS system so that the $\mathrm{CO}_{2}$ (and brine) form a potential source of hazard, wells and faults comprise the potential leakage pathways, and impacts occur to compartments.

\section{Evaluating Impacts}

Impacts of $\mathrm{CO}_{2}$ to compartments are evaluated in the CF by modeling and simulation of proxy concentrations or fluxes. The $\mathrm{CF}$ does not calculate impacts of $\mathrm{CO}_{2}$ (or brine) on particular individuals or species within a compartment, as is done for example using exposure and behavior modeling (e.g., McKone, 1993). Instead, the CF assumes that there are agreed-upon limits on $\mathrm{CO}_{2}$ or brine concentrations within the compartment as a whole, or on fluxes into the compartment, that can be established to ensure acceptable impact to the compartment. The numerical value of these limits will be specified in regulations that may vary by country but will presumably be scientifically based, perhaps on natural analogue studies. Whether a concentration- or flux-based limit is appropriate depends on the context and compartment. For example, for modeling $\mathrm{CO}_{2}$ impact to the HS compartment, it may be most convenient to set a concentration-based limit since the safety standards for $\mathrm{CO}_{2}$ exposure are given in terms of concentration of $\mathrm{CO}_{2}$ in air. In contrast, the ECA 
compartment impacts will be best modeled using a flux-based limit. The methods used in the CF to calculate fluxes and concentrations are reservoir simulation for the $\mathrm{CO}_{2}$ source and brine displacement process, and well and fault flow models for leakage up the conduits.

\section{Likelihood of Impact and Risk}

The CF is a risk-based approach that uses two likelihoods to estimate probability of leakage. The first is the likelihood of intersection of the $\mathrm{CO}_{2}$ (or brine) source with a conduit. The second is the likelihood of intersection of the conduit and a compartment. The product of these likelihoods is the probability of the given source-to-compartment leakage scenario. The risk associated with that leakage is the product of the likelihood of leakage and the impact of that leakage event. The probabilities of source/conduit and conduit/compartment intersections are site-specific (e.g., they depend on $\mathrm{CO}_{2}$ injection volume, number of wells per unit area) and are discussed below.

Acceptable risks from $\mathrm{CO}_{2}$ or brine leakage will be those below a threshold provided by external sources such as regulators or carbon credit insurers. In Figure 2, we present the abstracted CF compartments with potential intersections of the source $\left(\mathrm{CO}_{2}\right)$ and conduits, and the conduits and compartments indicated by dotted lines.

\section{Plume Migration}

The source for the leakage scenarios is determined by the movement of the $\mathrm{CO}_{2}$ plume during and after injection, and by the brine movement associated with $\mathrm{CO}_{2}$ injection. The plume movement can be estimated with reservoir simulation software. This can be done on a site-by-site basis by suitably skilled CF users. To make the CF more widely accessible, a catalog of three-dimensional reservoir simulations of $\mathrm{CO}_{2}$ injection and migration was developed using the CMG-GEM multiphase-flow

compositional numerical simulator. The Peng-Robinson equation of state was tuned to the 
$\mathrm{CO}_{2} /$ brine system (Kumar, 2008). Constant-rate injection is specified at the center of the generic model reservoir. At the boundaries of the grid, constant-pressure conditions are imposed to model an infinite-acting system. The catalog of cases used in this study focused on the extent of the $\mathrm{CO}_{2}$ plume. The same catalog offers reasonably accurate estimates of the spatial extent of large pressure elevations (e.g., greater than 7 bar ( 100 psi)). However, the use of constant pressure boundary conditions at a large but finite distance from the injection well means that estimated extent of small pressure rises (e.g., less than 0.3 bar ( $\sim 5$ psi)) are less accurate.

A large number of cases were simulated with a range of combinations of key reservoir properties such as thickness, dip, porosity, permeability, permeability anisotropy, injection interval, and injection rate (Kumar, 2008). The significant output from the catalog includes time for $\mathrm{CO}_{2}$ to migrate to the top of the reservoir, size of $\mathrm{CO}_{2}$ plume as a function of time, and pressure in the reservoir. These key output results can be interpolated for cases that do not exactly match catalog inputs.

\section{Work Flow}

The overall work flow of the CF approach is summarized in Figure 3. External inputs are required to characterize the site and define the reservoir, injection plan, and time frame. These inputs constrain the conditions and properties needed to estimate the $\mathrm{CO}_{2}$ (source) plume location, footprint size, and pressure perturbation. The estimate can be obtained from a suitably sophisticated reservoir simulation, or from a catalog of pre-computed simulations as discussed above. Next the CF uses external inputs on wells and faults, typically the plan-view spatial density and depths of abandoned wells and conductive faults. The likelihood of the plume intersecting the conduits is a function of the plume size and conduit spatial density. The output of the reservoir simulation is fed to the 
conduit flow model to calculate fluxes and/or concentrations within compartments under the assumption that they intersect. Using the externally supplied limits on concentrations or fluxes in the compartments, the value calculated by the CF either exceeds the limit (is an impact) or falls below the limit (is not an impact). The severity of the impact can be calculated by the degree to which a flux or concentration exceeds the limit, e.g., as given by the area between the limit and the flux or concentration curve in a plot of flux or concentration versus time. The risk can then be calculated as the product of the impact severity and the likelihood of the corresponding intersection with conduits (leakage scenario) occurring. Comparing the calculated CLR to the externally provided threshold, the CF determines whether the leakage risk is acceptable. If the CLR is above the threshold, changes to the injection plan or refinements in site characterization may be made resulting in decreased CLR. Although written in terms of CLR for brevity, the CF analysis of BLR follows the same flow process.

\section{Discussion of CF Methods}

The CF approach is intended to be simple and transparent. We achieve simplicity by stripping the system down into its fundamental component, namely the $\mathrm{CO}_{2}$ (or brine) source, conduits for leakage, and compartments where impacts may occur. We achieve further simplicity by using proxy fluxes or concentrations as proxies for impacts, and by handling uncertainty through simple intersection probabilities of conduits and source, and conduits and compartments. Transparency is achieved through the use of formal terminology and a consistent framework for calculating leakage risk. The framework relies on models of the physical processes during and after $\mathrm{CO}_{2}$ injection.

We have aimed to make the CF an accepted approach by making it accessible to a wide variety of

users. One of the key design features is the option to query from a catalog of pre-computed 
simulation results rather than requiring users to be familiar with sophisticated flow and transport models. While the CF can also use site-specific simulations, the catalog greatly increases accessibility and will be of interest to many users especially for early GCS risk assessments. We envision the users of the CF to be environmental scientists, engineers, and hydrogeologists who may or may not be familiar with running reservoir simulators.

\section{Case Study}

\section{Introduction}

In this section we apply the $\mathrm{CF}$ to a purely hypothetical geologic $\mathrm{CO}_{2}$ storage project targeting the down-dip water leg of the Fulshear natural gas storage reservoir southeast of Katy, Texas (USA) (Figure 4). The purpose of presenting this case study is to demonstrate the CF and its methods; the CF results for the case study are entirely secondary. Referring to the flow chart in Figure 3, site characterization data such as that presented below combined with an injection plan are the fundamental data needed as external input to the CF. The Fulshear site was chosen as a case study for several reasons: (1) its geology and hydrology are typical of many Texas Gulf Coast sites that may be actual candidates for $\mathrm{CO}_{2}$ storage; (2) the area is a pipeline corridor and numerous largescale power-plant sources of $\mathrm{CO}_{2}$ are nearby; (3) there is a large amount of data for the site available in the public domain by virtue of the Fulshear gas storage reservoir having been licensed within the last 20 years for natural gas storage (RRC, 1991); and (4) the area contains vulnerable entities (aquifers, hydrocarbon resources, and a rapidly growing residential population) useful for testing with the CF. The information used in the case study is representative of the level of information that a typical operator would be able to access with limited effort for a site located in the Texas Gulf 
Coast. Here we provide only an overview of the analysis to demonstrate the application of the CF. Details of the site and case study are documented in an internal report (Oldenburg et al., 2008).

\section{Storage and Injection Scenario}

The Fulshear gas reservoir is located in a roll-over anticline bounded to the NW by a SE-dipping fault (Figure 5). The scenario we consider involves injecting $\mathrm{CO}_{2}$ at a depth of 2,165 $\mathrm{m}(7,100 \mathrm{ft})$ into the Hillebrenner Sand approximately $6.3 \mathrm{~km}$ (3.8 mi) SE of the Fulshear fault, $3.5 \mathrm{~km}(2.1 \mathrm{mi})$ from the gas-water contact (Figure 4). The scenario considers a single-well injection with screen across the entire $15 \mathrm{~m}$ (50 ft) thickness of the formation. The injection rate is set constant at 0.8 $\mathrm{Mt} / \mathrm{yr}$ for 30 years, for a total of $24 \mathrm{Mt} \mathrm{CO}_{2}$ injected. This injection rate was chosen to avoid exceeding fracture pressure. In terms of the CF, the storage region is defined as the Hillebrenner Sand with lateral boundaries located at a radius of $4 \mathrm{~km}(2.5 \mathrm{mi})$ from the injection well.

\section{Site Characterization}

\section{Surface}

The Fulshear site is located on a flat coastal plain with land use predominantly small farming and ranching or suburban residential. There are numerous streams and wet lowlands with no major rivers or hills in the area. Climate is like that of Houston, with warm temperatures, high humidity, moderate precipitation, and light winds.

\section{Subsurface}

The reservoir is located in the Hillebrenner Sand at the top of the fluvio-deltaic Yegua Formation at a depth of approximately 2,165 m (7,100 ft). The Hillebrenner here consists of a channel of average width $900 \mathrm{~m}$ (2,900 ft) incising an earlier thinner sheet of sand. The blanket sand thickness varies from 1-4 m (3-14 ft) while that of the channel sand ranges from 10-19 m (35-62 ft) (RRC, 1991). 
The Hillebrenner dips $\sim 1^{0}$ to the SE. The geothermal gradient in the area is estimated to be 32 ${ }^{\circ} \mathrm{C} / \mathrm{km}\left(1.75{ }^{\circ} \mathrm{F} / 100 \mathrm{ft}\right)$ (Woodruff et al., 1984) resulting in a reservoir temperature of approximately $88^{\circ} \mathrm{C}\left(190{ }^{\circ} \mathrm{F}\right)$.

The generalized hydrostratigraphy of the Fulshear area is presented in Table 2 with emphasis on flow properties relevant to $\mathrm{CO}_{2}$ and brine migration (Smith and Goodwyn, 1962; Baker, 1986, and references in Table 2). In general, the section above the Hillebrenner Sand contains $470 \mathrm{~m}$ (1,550 ft) of mostly claystones (105 $\mathrm{m}$ at the top of the Yegua, $350 \mathrm{~m}$ of the Jackson Group shales and sands, and $15 \mathrm{~m}$ at the base of the Lower Vicksburg) which form a seal on the injection formation before the first permeable unit at the base of the Lower Vicksburg. The Lower Vicksburg (65 $\mathrm{m}$ total)

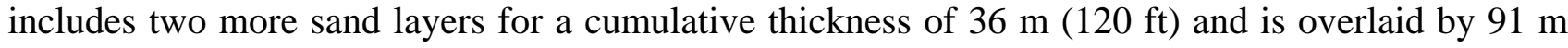
(300 ft) of additional confining Vicksburg rocks, $500 \mathrm{~m}$ (1650 ft) of mostly confining Catahoula (updip equivalent of the Frio), and $290 \mathrm{~m}$ (950 ft) of Fleming/Oakville Sands which contains the Jasper aquifer. Catahoula/Frio and Fleming/Oakville are separated by $25 \mathrm{~m}(80 \mathrm{ft})$ of the Anahuac Formation, a regionally extensive marine shale but close to its pinchout edge in the Fulshear area. The Oakville Sands are separated from the next permeable unit up by $120 \mathrm{~m}(400 \mathrm{ft})$ of confining Fleming/Burkeville Shale. Above this confining unit resides the mostly permeable formations with at total thickness of $620 \mathrm{~m}$ (2,030 ft) of the Goliad, Willis, and other younger deposits which contain the Evangeline and Chicot aquifers. The three top-most aquifers and adjacent aquitards are shown in the geologic cross-section of Figure 6, along with the approximate location of the hypothetical injection well (red vertical line), and limit of USDW (horizontal line). 


\section{Potential Leakage Pathways}

Wells

As shown in Figure 4, oil and gas exploration and production wells dot the Fulshear area, with many wells more than 50 years old (RRC well database, 2005). Within the Fulshear natural gas reservoir, 13 out of 39 existing wells had to be properly plugged as part of the permitting process for startup of gas storage operations (RRC, 1991). A total of 73 wells penetrated the Hillebrenner Sand (RRC, 1991) in the Fulshear gas storage area. Injection pressure is limited by permit to a maximum of $~ 18$ MPa (2650 psi) (RRC, 1991). Original bottom-hole pressure was hydrostatic at 21 MPa (3044 psi (RRC, 1991).

In addition to deep hydrocarbon wells, there are also shallower water wells in the Fulshear area (Figure 4). While neither the large municipal water wells nor the shallower private water wells penetrate anywhere near the depths of the hypothetical injection target, such wells could be secondary leakage pathways if $\mathrm{CO}_{2}$ or brine migrated out of the Hillebrenner and moved upwards significantly.

Faults

The Fulshear fault that forms the gas-storage reservoir trap results from a reactivation of the deeper seated Wilcox fault zone and does not reach the ground surface (e.g., Ewing, 1986). The Fulshear fault is attenuated in the clayey Jackson Group less than $600 \mathrm{~m}(2,000 \mathrm{ft})$ above the Hillebrenner Sand. The shale gouge ratio (SGR) is likely $50 \%$ in faults intersecting the Hillebrenner Sand implying a sealing rather than conductive character. 


\section{Potential Impacts}

Surface

At the surface, there is a mix of suburban housing, agricultural fields, and a golf course within a twomile radius of the hypothetical injection area $6.3 \mathrm{~km}(3.8 \mathrm{mi}) \mathrm{SE}$ of the Fulshear fault. Aside from creeks and associated small depressions along streams, and trees in the area, there is no obvious sensitive environmental land (e.g., state or national parks). Current land use includes a history of natural gas production.

\section{Subsurface}

The southern boundaries of the Katy oil and gas field are located $\sim 3 \mathrm{~km}$ (2 mi) to the north of the Fulshear gas storage facility on the upthrown side of the Fulshear fault. Because the scenario for $\mathrm{CO}_{2}$ injection considers the downdip water leg of the Hillebrenner Sand SE of the Fulshear fault, the hydrocarbon resources in the Katy oil and gas field are not considered vulnerable to $\mathrm{CO}_{2}$ leakage. The natural gas of the Fulshear gas storage facility will be directly impacted by $\mathrm{CO}_{2}$ injection. Assuming injection $3.5 \mathrm{~km}(2.1 \mathrm{mi})$ away from the gas reservoir, the first impact would be brine displacement and pressurization with corresponding decrease in volume of the gas (i.e., movement of gas-water contact to the NW). The second impact could be migration of $\mathrm{CO}_{2}$ into the gas storage reservoir, but this would be a long time (many decades to centuries) after injection because of the distance between the injection well and gas reservoir. Because the Fulshear gas storage reservoir is part of the proposed $\mathrm{CO}_{2}$ storage region, the impact of $\mathrm{CO}_{2}$ on the natural gas would not be due to leakage by definition and therefore such impact does not contribute to risk from the point of view of the CF.

\section{Aquifers}


The Jasper Aquifer lies approximately 1,000 m (3,300 ft) above the Fulshear $\mathrm{CO}_{2}$ sequestration target, with the Evangeline, and Chicot Aquifers at shallower depths (Figure 6). A total dissolved solids concentration of $3,000 \mathrm{mg} / \mathrm{L}$ is locally recognized as the down-dip limit of freshwater (Ashworth and Hopkins, 1995) and the Jasper aquifer is considered too saline to be a direct source of fresh water (Thorkildsen, 1990). However, an underground source of drinking water (USDW) is defined by the USEPA as having TDS $<10,000 \mathrm{mg} / \mathrm{L}$. The three Gulf Coast Aquifers in the vicinity of the Fulshear reservoir have a TDS $<10,000 \mathrm{mg} / \mathrm{L}$ and as such are part of the USDW compartment. The next formation down with a permeability high enough to qualify as an aquifer (Frio) has a TDS $>10,000 \mathrm{mg} / \mathrm{L}$.

The City of Katy extracts water from six wells (Figure 4) screened in the Evangeline Aquifer at depths of approximately 166-290 m (550-950 ft) (TCEQ, 2007). The average production was approximately 1.75 MGD (6,590 $\mathrm{m}^{3} /$ day) in the year 2000 (TWDB, 2002).

\section{Reservoir Simulation}

The CF uses input on subsurface conditions to define model properties needed to simulate $\mathrm{CO}_{2}$ injection and migration within the storage region (source), through the conduits (faults and wells), and into potentially vulnerable entities (compartments). CF users can query the catalog to determine $\mathrm{CO}_{2}$ plume migration for input in the CF. For this case study, injection is carried out for $30 \mathrm{yrs}$ followed by plume migration for 1,000 yrs. The injection well is completed fully over the reservoir thickness. We present results from a simulation with properties as given in Table 3 to match approximately Hillebrenner Sand properties. For simplicity and in the absence of data, capillary pressure was neglected, and residual gas and liquid saturations were set to 0.25 , although the liquid saturation can fall below this value due to evaporation into the $\mathrm{CO}_{2}$. As shown, reservoir thickness 
is set at $15.2 \mathrm{~m}$ (50 ft), porosity 25\%, permeability $136 \mathrm{md}$, and dip $1^{\circ}$ to the SE. From well logs of the Fulshear reservoir, it was found that the reservoir contains shale barriers that extend laterally to at least one well spacing $(518 \mathrm{~m}(1,700 \mathrm{ft}))$. From this information, an equivalent $k_{v} / k_{h}$ was calculated to be 0.04 (Kumar et al., 2007).

Simulations of the injection scenario suggest the $\mathrm{CO}_{2}$ plume will travel $2.6 \mathrm{~km}(1.6 \mathrm{mi})$ radially away from the well after 30 yrs of injection (Figure $7 \mathrm{a}$ and b). After injection stops at $30 \mathrm{yrs}$, the plume moves very slowly in the up-dip direction under gravity such that after a total time of $100 \mathrm{yrs,}$ the up-dip plume extent is $2.8 \mathrm{~km}(1.7 \mathrm{mi})$ from the injection well (Figure 7c and d). This slow migration occurs because as the plume migrates up dip, $\mathrm{CO}_{2}$ is trapped at residual saturation by capillary forces or dissolved in brine (mineral trapping is not modeled here). The model predicts that after $100 \mathrm{yrs}$, only $20 \%$ of total injected $\mathrm{CO}_{2}$ is mobile, and after $1000 \mathrm{yrs}$, only $10 \%$ is mobile. The most mobile $\mathrm{CO}_{2}$ is located just beneath the top seal where $\mathrm{CO}_{2}$ saturation is the highest.

\section{Probability of plume Intersection with Wells and Faults}

The Fulshear site contains numerous wells in various states of use and abandonment located within $2.8 \mathrm{~km}(1.7 \mathrm{mi})$ of the proposed $\mathrm{CO}_{2}$ injection well. Because of the numerous wells in the Fulshear area, there is a very high probability ( 100\%) that the $\mathrm{CO}_{2}$ injection plume will encounter at least one well in 30 years of injection. In fact, the $\mathrm{CO}_{2}$ plume is expected to intersect the nearest well in approximately 12 yrs. The pressure at the well when the plume reaches it is predicted by the model to be $3.5 \mathrm{MPa}$ (510 psi) above hydrostatic. After injection is stopped at $30 \mathrm{yrs}$, the pressure at the well drops to only $0.58 \mathrm{MPa}(85 \mathrm{psi})$ above hydrostatic. 
Note that it is also very likely that faults and fractures will be encountered by the $\mathrm{CO}_{2}$ plume, but as discussed above, faults in the area are expected to be non-conductive. Therefore, the primary potential leakage conduits are the wells in the area.

\section{Probability of Wells Being Conductive}

In the hypothetical $\mathrm{CO}_{2}$ storage scenario considered here, injected $\mathrm{CO}_{2}$ may encounter multiple wells in the water leg. These wells likely vary in age and condition, making it difficult to assign a probability distribution for well permeability for the wells. Leakage cannot occur through intact cement, but can occur through highly degraded or fractured cement and the associated imperfect bonding with the formation or the casing or both. In all likelihood, wells will be effectively nonconductive. For risk assessment purposes, we consider the possibility of well leakage by defining three non-zero effective permeabilities that likely span the range of possible conductivities from wells with highly degraded cement (e.g., $100 \mathrm{md}\left(10^{-13} \mathrm{~m}^{2}\right)$ and $\left.1000 \mu \mathrm{d}\left(10^{-15} \mathrm{~m}^{2}\right)\right)$ to intact cement $\left(10 \mu \mathrm{d}\left(10^{-17} \mathrm{~m}^{2}\right)\right)$. With analogy to common materials, the very permeable case would correspond to a well filled with silty sand, or a fracture of width $50 \mu \mathrm{m}$ in well cement (Huerta and Bryant, 2007), the intermediate case to a well filled with silt, and the lowest permeability to a well filled with shale or clay (Freeze and Cherry, 1979).

\section{Well leakage model}

A leaking well is a potential conduit to allow $\mathrm{CO}_{2}$ to migrate from the storage reservoir to shallower depths. The leakage model we use is a simple one-dimensional single-phase model that includes the possibility of flow into the adjacent formation (flow up uncased well or flow between the casing and formation). Upward flow in the well is referred to as leakage, while lateral flow from the well into adjacent formations is referred to as attenuation. Attenuation can occur depending on the layer 
permeability and overpressure in the well relative to the hydrostatic far-field pressure in each layer. This well-flow model is used here simply to demonstrate the CF; actual applications of the CF will require a more sophisticated well-flow model.

In the case study, we assume leakage along a generic well connecting the top of the reservoir at 2,134 $\mathrm{m}(7,000 \mathrm{ft})$ to a depth of $40 \mathrm{~m}(130 \mathrm{ft})$ below the ground surface. The pressure is assumed hydrostatic in the well, and $0.55 \mathrm{MPa}$ ( $80 \mathrm{psi}$ ) above hydrostatic at the bottom, similar to the 0.58 MPa (85 psi) bottom-hole pressure calculated for the nearest well by reservoir simulation. The layer thicknesses and formation properties used in the model are given in Table 1. The well diameter in all cases is assumed to be $0.10 \mathrm{~m}$ (4 in).

In Figure 8, we show results of the well-flow model in terms of $\mathrm{CO}_{2}$ mass flux vs. depth for three different effective well permeabilities. Note first that regardless of well permeability, approximately $30 \%$ of the $\mathrm{CO}_{2}$ leakage flux occurs into the deepest attenuation layer directly above the reservoir seal (Jackson Group), while 70\% of the leakage persists to the top of the well. This result confirms that attenuation near the storage reservoir has a pronounced effect on shallower attenuation and efflux at the top of the well (Minkoff et al., 2007). The reason for this behavior is that pressure becomes very nearly hydrostatic once significant attenuation occurs, thus eliminating the driving force for lateral flow from the well at higher elevations. The highest leakage rate calculated here is approximately $10^{-4} \%$ of the injection rate, while the lowest is $10^{-8} \%$. 


\section{Potential Impacts to Compartments}

\section{HMR}

There are no identified hydrocarbon resources directly above the down-dip water leg of the Fulshear gas reservoir, nor above the gas reservoir itself. Thus, $\mathrm{CO}_{2}$ leakage up the well will not impact HMR. We assume here that the carbon sequestration scenario under analysis involves committing the gas storage reservoir to $\mathrm{CO}_{2}$ storage rather than natural gas storage after many decades thereby eliminating this potential impact by definition.

\section{USDW}

If the leaking well connects from the reservoir to the ground surface and is open at the top, there will be very little impact to USDW because attenuation occurs mostly into the Lower Vicksburg at depth leaving little driving force for $\mathrm{CO}_{2}$ attenuation into the aquifers. If there is a clay or cement backfill at the top of the well, the worst case is that all of the well leakage flux enters the aquifers. The wellflow model predicts a range of $\mathrm{CO}_{2}$ fluxes into the aquifers at the site from $3.6 \times 10^{-3} \mathrm{~kg} \mathrm{~m}^{-2} \mathrm{~s}^{-1}$ to $3.6 \times 10^{-7} \mathrm{~kg} \mathrm{~m}^{-2} \mathrm{~s}^{-1}$ (Figure 8). If we multiply these fluxes by the area of the well, assumed to be 10 $\mathrm{cm}$ (4 in) in diameter, we obtain a range of flow rates from $2.8 \times 10^{-5} \mathrm{~kg} \mathrm{~s}^{-1}\left(2.4 \mathrm{~kg}\right.$ day $\left.^{-1}\right)$ to $2.8 \times$ $10^{-9} \mathrm{~kg} \mathrm{~s}^{-1}\left(2.4 \times 10^{-4} \mathrm{~kg} \mathrm{day}^{-1}\right)$. At standard conditions of 1 bar and $20{ }^{\circ} \mathrm{C}$, the density of $\mathrm{CO}_{2}$ is 1.8 $\mathrm{kg} \mathrm{m} \mathrm{m}^{-3}$, making these flow rates approximately $1.3 \mathrm{~m}^{3}$ day $^{-1}\left(46 \mathrm{ft}^{3} \mathrm{day}^{-1}\right)$ and $0.00013 \mathrm{~m}^{3}$ day $^{-1}$ $\left(0.0046 \mathrm{ft}^{3}\right.$ day $\left.^{-1}\right)$.

In the CF, these flow rates into the USDW compartment are the proxies for impact. In the absence of regulatory upper limit on $\mathrm{CO}_{2}$ flux into an aquifer, we compare the pumping rates from wells at Katy which are of order $1000 \mathrm{gpm}\left(\sim 5000 \mathrm{~m}^{3}\right.$ day $\left.^{-1}\right)$ making them $10^{3}$ to $10^{7}$ times larger by volume than the $\mathrm{CO}_{2}$ leakage rate. Another way to look at it is to assume all of the leaking $\mathrm{CO}_{2}$ dissolves 
into the water (assuming $\mathrm{CO}_{2}$ solubility is 2\%), thereby affecting $2.4 \mathrm{~kg}$ day $^{-1} \times 1000 \mathrm{~kg} \mathrm{H}_{2} \mathrm{O} / 20 \mathrm{~kg}$ $\mathrm{CO}_{2}=120 \mathrm{~kg} \mathrm{H}_{2} \mathrm{O}$ day $^{-1}$, or $0.12 \mathrm{~m}^{3}$ day $^{-1}$. This represents approximately $0.002 \%$ of the typical pumping rates from the aquifers. Thus the calculated flow rates are likely small enough as to be inconsequential.

\section{HS and NSE}

Assuming the well extends to the ground surface, the fluxes predicted by the well-flow model are 110,000 times a typical net ecosystem exchange (NEE) value (Baldocchi and Wilson, 2001). As with the USDW compartment, the CF relies on an externally supplied upper limit to determine if the calculated fluxes produce a negative impact on the HS and NSE compartments. In the absence of this upper limit, we can again speculate about potential impacts. Focusing only on the high end of the predicted $\mathrm{CO}_{2}$ flux, we have potentially 10,000 times a typical NEE flux emanating from a single well. If we assume this flux is averaged over one hectare by wind dispersion at the surface, we obtain on average a flux equal to a typical NEE. This flux is negligible and difficult even to detect. The one instance in which there might be impact is if the flux occurs directly into a basement or other enclosed space. Given the suburban and rural nature of the land use near the site, its relatively flat topography, and recent history of hydrocarbon exploration and production, we conclude that it is highly unlikely that buildings exist on top of leaking wells and therefore impacts to the HS compartment are likely to be negligible.

As for the environment (NSE compartment), potential impact could occur locally near the well as $\mathrm{CO}_{2}$ migrates upward and is emitted near the ground surface. If the $\mathrm{CO}_{2}$ emission is into the ambient air (above-ground discharge), we expect atmospheric dispersion processes to mix and 
dissipate the emitted $\mathrm{CO}_{2}$. Even low wind speeds would be expected to disperse $\mathrm{CO}_{2}$ to negligible concentrations at these relatively low fluxes (Oldenburg and Unger, 2004).

If the $\mathrm{CO}_{2}$ were emitted into a surface water body (e.g., creek or wetland) with depth less than $0.6 \mathrm{~m}$ (2 ft) as may occur seasonally in the Katy area, the larger fluxes would be transported upward through the water column as bubbles and emanate from the surface (Oldenburg and Lewicki, 2006) into the ambient atmosphere where it would be dispersed as discussed above. Such shallow water bodies are themselves well mixed by wind or currents and thus we expect rapid equilibration with the atmosphere and no possibility of buildup of dense $\mathrm{CO}_{2}$-charged water at depth.

If the $\mathrm{CO}_{2}$ were emitted just below the ground surface, concentrations could build up to high levels in the soil even if the flux is small (Oldenburg and Unger, 2003). However, the effects are expected to be very local as $\mathrm{CO}_{2}$ will seep upwards into the ambient air from such a source and rapidly disperse above the ground surface in the presence of wind (Oldenburg and Unger, 2004). Although not quantified in the $\mathrm{CF}$, the local impact would be elevation of $\mathrm{CO}_{2}$ concentrations in soil gas in the unsaturated zone, and acidification of local soil moisture with corresponding impacts on roots of local plants.

As we have seen above, on the scale of one hectare, the effective flux from the well is equal to a typical NEE which would not only cause no impact but would also be difficult to detect (e.g., see Lewicki et al., 2005). For comparison, the average $\mathrm{CO}_{2}$ flux emanating from the 2-in diameter tailpipe of an automobile that gets $20 \mathrm{mpg}$ traveling at $60 \mathrm{mph}$ is $3.6 \mathrm{~kg} \mathrm{~m}^{-2} \mathrm{~s}^{-1}$. This flux is 1000 times larger than the largest well leakage flux calculated here. As for the smallest leakage fluxes 
calculated with the well leakage model, no impact is expected given that the flux is approximately the same as a typical biogenic $\mathrm{CO}_{2}$ flux. Nevertheless, the potential environmental impact to the NSE caused by $\mathrm{CO}_{2}$ leakage on a very local scale in the subsurface around the well is likely the main impact driver for the $\mathrm{CO}_{2}$ leakage risk calculation.

\section{ECA}

Impact to the ECA compartment is found to be negligible. First on the emission credits side, the largest leakage rate calculated here is $2.8 \times 10^{-5} \mathrm{~kg} \mathrm{~s}^{-1}\left(2.4 \mathrm{~kg} \mathrm{day}^{-1}\right)$ assuming leakage is over the entire diameter of the well. Compared to the $\mathrm{CO}_{2}$ injection rate of $0.8 \mathrm{Mt} \mathrm{yr}^{-1}\left(25 \mathrm{~kg} \mathrm{~s}^{-1}\right.$ or $2200 \mathrm{t}$ $\operatorname{day}^{-1}$ ), the leakage rate is approximately $10^{-4} \%$ (one part per million) of the injection rate. Second, on the atmospheric degradation side, we can compare this emission to that from an automobile and we find it is equivalent to driving a $20 \mathrm{mpg}$-car approximately $5 \mathrm{mi}$ per day. Finally, leakage is unlikely to be over the entire radius of the well but rather through a small portion of the well cross section, making the above leakage rate calculations conservative estimates. We conclude that impacts to ECA are clearly well below those needed to drive the risk assessment at the site.

\section{$\mathrm{CO}_{2}$ Leakage Risk}

Effective trapping is calculated in the CF in terms of $\mathrm{CO}_{2}$ leakage risk (CLR) which is the product of impact and probability of occurrence of the processes leading to that impact. As discussed above, the impact driver appears to be the NSE compartment, and the environment local to the well in the case that $\mathrm{CO}_{2}$ leaks up the well into the shallow subsurface in particular. Because of the size of the plume and relatively small spacing between wells at Fulshear, the probability of intersection of the plume with a well is considered to be $100 \%$. Assessing whether or not wells at Fulshear will be conductive is beyond the scope of this study, hence the four-orders-of magnitude variation employed in the well-flow modeling. Although the purpose of this case study is to demonstrate the CF 
approach, we can conclude from the analysis that there would be non-zero risk of short-term impact to the local environment around a leaking well due to $\mathrm{CO}_{2}$ discharge in the shallow subsurface (NSE). Local and regional regulators would have to work with project proponents to further constrain well-flow properties, remediate some of the wells, or decide that the risk was acceptable and $\mathrm{CO}_{2}$ could be considered to be effectively trapped.

To demonstrate how the CLR would be calculated in the case of non-100\% intersection probability, we can consider a purely hypothetical analysis that assumes that the probability of the plume intersecting a well with the highest conductivity (permeability of $10^{-13} \mathrm{~m}^{2}$ corresponding to highly degraded cement) ranges from one in one hundred to one in a million per year. Using the corresponding highest calculated flux of $3.6 \times 10^{-3} \mathrm{~kg} \mathrm{~m}^{-2} \mathrm{~s}^{-1}$ sustained for a month as the proxy impact, and referring to this as a $j_{\text {NSE_impact }}$-month, the CLR ranges from a 1/100 to $1 / 1,000,000$ chance of obtaining a $j_{\text {NSE_impact }}$-month per year. Implicit here is the assumption that mitigation measures would be undertaken to eliminate the well leakage within a month as effects are observed.

\section{Discussion}

As mentioned in the above description of the CF approach and case study, the CF relies on externally supplied limits on $\mathrm{CO}_{2}$ fluxes into, and/or concentrations in, compartments to define whether impacts occur. By keeping these limits unspecified, the CF can be flexible to adjust to whatever regulations are adopted by various regional and national governments. This flexibility extends also to evolution of regulations over time. The point of our work is to establish a framework that will use such limits and to define how they will be used. We leave it to other research projects to present scientifically defensible studies to establish numerical values for these limits to fluxes or concentrations for various environments and conditions. 
The CF also maintains flexibility in the establishment of thresholds for acceptability of CLR and BLR, where risk is defined as the product of the likelihood of a particular impact event occurring and that particular impact. The dimensions of CLR and BLR are impact per time. Making use of the proxy impact concept where impact is, for example, a flux above a certain limit sustained over a day, the typical units of CLR and BLR are $\mathrm{kg} \mathrm{m}^{-2} \mathrm{~s}^{-1}$ day/yr, which can be abbreviated as a flux-day per year. For example, a CLR to a home might be predicted to be a one in a thousand chance per year of having a day with at least a flux of $\mathrm{CO}_{2}$ of $10^{-5} \mathrm{~kg} \mathrm{~m}^{-2} \mathrm{~s}^{-1}$. This would be a $0.1 \%$ chance per year of a $10^{-5} \mathrm{~kg} \mathrm{~m}^{-2} \mathrm{~s}^{-1}$ day. As with establishing limits for impacts, our work avoids establishing thresholds for leakage risk and instead focuses on establishing a framework for using such thresholds and maintains flexibility for whatever thresholds may be agreed upon regionally and over time.

In addition to regulations, limits, and thresholds, the GCS system, along with its potential impacts, can change over time making the risk profile change. For example, urbanization or other changing land uses can drastically change the HS and NSE compartment characteristics on time scales of years to decades. Or improvements in desalination technology, increased demands, or scarcity of water resources could change the definitions of USDW. In addition, earthquakes could occur, or faults could be reactivated to create or enhance potential leakage conduits. Insofar as most of these changes cannot be easily forecasted into the future, frameworks for assessing leakage risk will need to be updated from time to time as conditions change during a GCS project.

Modeling and simulation are fundamental elements of the CF approach. Acknowledging that performing credible simulations of $\mathrm{CO}_{2}$ and brine migration in subsurface reservoirs is a highly 
specialized skill, we endeavored to make the CF usable by people who are not specialists in numerical simulation. Our approach is to generate a catalog (database) of simulation results based on a large number of different combinations of properties likely to be encountered in GCS sites. We call this sophisticated modeling of simplified systems because the catalog consists of results from multiphase and multicomponent reservoir simulators (e.g., CMG-GEM and TOUGH2), but they are calculated typically for simple geometries with uniform properties. The CF user can then query from this catalog using specific properties for the site under consideration and estimate fundamental aspects of the injected $\mathrm{CO}_{2}$ such as plume radius, time for the plume to migrate to the top of the reservoir, pressure at given conduit locations, etc.. The main benefits of this approach are that (1) non-reservoir engineers can make defensible predictions of plume migration, and (2) plume migration will be consistently assessed using the same basic catalog across all users and sites. Finally, while we advocate the catalog approach for CF applications, there is nothing in the CF that precludes the use of site-specific modeling when the catalog does not cover the needed range of parameters, or when more detailed model results are desired such as for the case that the catalog results are suspected to lead to an underestimation of leakage risk. Any additional site-specific model results carried out can then be entered into the catalog by users around the world potentially to refine and broaden the catalog's applicability and accuracy. Again, rather than be prescriptive about using the catalog or using a site-specific simulation, the CF instead forms the framework for simulation results in general to be used in a consistent and logical way.

In the case study, we used a very simple well-flow model to demonstrate the CF approach. We also appealed to dispersion above ground as a mechanism to disperse $\mathrm{CO}_{2}$ seepage from a well discharging to the air or shallow subsurface without actually modeling that process. At the time of 
this writing, we are in the process of developing a well-bore flow model and a density-dependent atmospheric dispersion model. The CF will accommodate both a catalog and site-specific approach to the modeling of the well-bore, fault, and atmospheric flow and dispersion processes analogous to the catalog of in-reservoir simulation results. The CF framework is general and flexible enough to accommodate alternative models if users so desire.

As with any analysis that makes use of models, there is a need to confirm that (1) the models used are accurate, defensible, and transparent, and (2) the way the CF uses model results is accurate and defensible. The models used for $\mathrm{CO}_{2}$ and brine migration in the reservoir to date have been CMGGEM and TOUGH2, both of which are well known (transparent) and respected simulation models. Transparency of the CF will diminish if users implement less well-known or not-publicly-available proprietary models. The well- and fault-flow models along with the atmospheric dispersion model we are currently developing will be documented publicly and available for distribution. As for validation of the CF analysis, limited validation can be done by applying the CF to case studies with known histories of injection or leakage. The ultimate validation will have to await wide acceptance of the CF approach and greater experience in GCS.

\section{Conclusions}

We have developed the CF approach for risk assessment of GCS sites based on the concept of effective trapping, which allows for potential leakage of $\mathrm{CO}_{2}$ or brine provided the associated risk is below agreed-upon thresholds. The goal of the CF is to be simple, transparent, and accepted. We achieve simplicity in the CF by assuming that the only potential leakage pathways are wells and faults. Further, we assume all of the vulnerable entities reside within a handful of compartments, and that impacts to compartments are calculated by proxy fluxes and concentrations. Transparency 
is achieved by making use of a catalog of simulation results rather than requiring a site-specific simulation for each site, although nothing in the framework precludes use of a site-specific simulation if desired. As for acceptance, we have endeavored to make the CF flexible so that it can be used in various regulatory jurisdictions.

We applied the CF to a hypothetical GCS site as a case study to demonstrate the approach. The case study revealed the need for data on conductivity of wells that may be intersected by the $\mathrm{CO}_{2}$ plume. In the absence of such data, ranges of properties must be used which leads to ranges of results of CLR. The case study also points out the need for research to define the limits for establishing impacts on compartments such as USDW and NSE.

\section{Acknowledgments}

We thank Navanit Kumar (UT) for generating the catalog of simulation results, Yingqi Zhang (LBNL) for modeling well-flow, and Sue Minkoff (Univ. of Maryland, Baltimore County) for developing the initial leak-off well-flow model. We thank Scott Imbus (Chevron) and Cal Cooper

(Conoco-Phillips) for support and encouragement. This work was supported in part by the $\mathrm{CO}_{2}$ Capture Project (CCP) of the Joint Industry Program (JIP), and by Lawrence Berkeley National Laboratory under U.S. Department of Energy Contract No. DE-AC02-05CH11231.

\section{References}

Ashworth, J. B. and J. Hopkins, Major and Minor Aquifers of Texas: Texas Water Development Board Report 345, 1995.

Bachu, S, and W.D. Gunter, Acid-gas injection in the Alberta basin, Canada: a $\mathrm{CO}_{2}$-storage experience, Geological Society, London, Special Publication 233: 225-234, 2004. 
Baker, E. T., Jr., Hydrology of the Jasper Aquifer in the Southeast Texas Coastal Plain: Texas Water Development Board Report 295, 64 p., 1986.

Baldocchi, D.D., and K.B. Wilson, Modeling $\mathrm{CO}_{2}$ and water vapor exchange of a temperate broadleaved forest across hourly to decadal time scales, Ecological Modelling, 142, 155-184, 2001.

Bebout, D. G., R. G. Loucks, S. C. Bosch, and M. H. Dorfman, Geothermal resources Frio Formation, Upper Texas Gulf Coast, The University of Texas at Austin, Bureau of Economic Geology Geological Circular 76-3, 47 p., 1976.

Benson, S.M., and L.R. Myer, Monitoring to ensure safe and effective geologic sequestration of carbon dioxide, IPCC workshop on geologic carbon sequestration, 2002.

Benson, S.M., R. Hepple, J. Apps, C.-F. Tsang, and M. Lippmann, Lessons learned from natural and industrial analogues for storage of carbon dioxide in deep geological formations, E.O. Lawrence Berkeley National Laboratory Report LBNL-51170, 2002.

Bowden, A.R., and A.J. Rigg, Assessing risk in $\mathrm{CO}_{2}$ storage projects, Austral. Petrol. Prod. and Explor. Assoc. J., 44(1), 677-702, 2004.

Clauser, C., Permeability of Crystalline Rocks, EOS, vol. 73(21), 233, 237, 238, American Geophysical Union, May 26, 1992.

Combes, J. M., The Vicksburg formation of Texas: depositional systems distribution, sequence stratigraphy, and petroleum geology: American Association of Petroleum Geologists, v. 77(11), p. 1942-1970, 1993.

Ewing, T. E., Structural styles of the Wilcox and Frio growth-fault trends in Texas: constraints on geopressured reservoirs: The University of Texas at Austin, Bureau of Economic Geology Report of Investigations No. 154, 86 p., 1986.

Fisher, W. L., Facies characterization of Gulf Coast Basin delta systems, with some Holocene analogues: Gulf Coast Association of Geological Societies Transactions, v. 19, p. 239-261, 1969.

Fisher, W. L., C. V. Proctor, W. E. Galloway, and J. S. Nagle, Depositional systems in the Jackson Group of Texas-Their relationship to oil, gas, and uranium: Gulf Coast Association of Geological Societies Association, v. 20, p. 234-261, 1970.

Freeze, R.A., and J.A. Cherry, Groundwater, Prentice Hall, p. 604, 1979.

Galloway, W. E., L. A. Jirik, R. A. Morton, and J. R. Dubar, Lower Miocene (Fleming) Depositional Episode of the Texas Coastal Plain and Continental Shelf: Structural Framework, Facies, and Hydrocarbon Resources: The University of Texas at Austin, Bureau of Economic Geology Report of Investigations No 150, 50 p., 1986. 
Hepple, R.P., Benson, S.M., Geologic storage of carbon dioxide as a climate change mitigation strategy: performance requirements and the implications of surface seepage, Environ. Geol., 47(4) , 576-585, 2005.

Huerta, N.J., and S.L. Bryant, Importance of $\mathrm{CO}_{2} /$ Cement Reactions: Analysis of Long-Term Cement Competence as Part of a Certification Framework for $\mathrm{CO}_{2}$ Sequestration, Sixth Annual Conference on Carbon Capture and Sequestration, Pittsburgh, PA, May 7-10, 2007.

Intergovernmental Program on Climate Change (IPCC) Special Report on carbon dioxide capture and storage, ISBN 92-969-119-4, http://www.ipcc.ch/activity/srccs/index.htm, 2005.

Kasmarek, M. C. and J. L. Robinson, Hydrogeology and Simulation of Ground-Water Flow and Land-Surface Subsidence in the Northern Part of the Gulf Coast Aquifer System, Texas. U.S. Geological Survey Scientific Investigations Report 2004-5102 in cooperation with the Texas Water Development Board and the Harris-Galveston Coastal Subsidence District, 111p., 2004.

Kumar, N., $\mathrm{CO}_{2}$ Sequestration: Understanding the plume dynamics and estimating risk, Univ. of Texas, Austin, Master’s Thesis, 2008.

Kumar, N., S. L. Bryant, J. -P. Nicot, , and C. M. Oldenburg, Simulation studies for geological $\mathrm{CO}_{2}$ storage certification framework (abs.), in Sixth Annual Conference on Carbon Capture \& Sequestration, May 7-10, Pittsburgh, Abstract \#116, 2007.

Lewicki, J.L., G.E. Hilley, and C.M. Oldenburg, An improved strategy to detect $\mathrm{CO}_{2}$ leakage for verification of geologic carbon sequestration, Geophys. Res. Letts., 32, L19403, 2005.

McKone, T.E., CalTOX: A Multimedia Total-Exposure Model For Hazardous-Wastes Sites: Part I: Executive Summary. prepared for the State of California, Department of Toxic Substances Control, Lawrence Livermore National Laboratory, Livermore, CA, UCRL-CR-111456PtI., 1993.

Minkoff, S. E., S. L. Bryant, J. -P. Nicot, and C. M. Oldenburg, 2007, Modeling leakage of $\mathrm{CO}_{2}$ along a fault for risk assessment (abs.), in Sixth Annual Conference on Carbon Capture \& Sequestration, May 7-10, Pittsburgh, Abstract \#053, 2007.

Oldenburg, C.M., Screening and ranking framework for geologic $\mathrm{CO}_{2}$ storage site selection on the basis of health, safety, and environmental risk, Environmental Geology, 54, 1687-1694, 2008.

Oldenburg, C.M., and J.L. Lewicki, On leakage and seepage of $\mathrm{CO}_{2}$ from geologic storage sites into surface water, Environmental Geology, 50(5), 691-705, 2006.

Oldenburg, C.M., and A.J.A. Unger, Coupled vadose zone and atmospheric surface-layer transport of $\mathrm{CO}_{2}$ from geologic carbon sequestration sites, Vadose Zone Journal, 3, 848-857, 2004.

Oldenburg, C.M., and A.J.A. Unger, On leakage and seepage from geologic carbon sequestration sites: unsaturated zone attenuation, Vadose Zone Journal, 2(3): 287-296, August 2003. 
Oldenburg, C.M., S.L. Bryant, J.-P. Nicot, N. Kumar, S.E. Minkoff, and Y. Zhang, Assessment of $\mathrm{CO}_{2}$ leakage risk for hypothetical $\mathrm{CO}_{2}$ injection southeast of the Fulshear Gas Storage Reservoir at Katy, Texas, Lawrence Berkeley National Laboratory Report LBNL-xxxxx, April, 2008.

Pacala, S., and R. Socolow, Stabilization Wedges: Solving the Climate Problem for the Next 50 Years with Current Technologies, Science 305(5686), 968-972, 13 August 2004.

Paul, J.H., J.B. Rose, S.C. Jiang, X. Zhou, P. Cochran, C. Kellogg, J.B. Kang, D. Griffin, S. Farrah, and J. Lukasik, Evidence for groundwater and surface marine water contamination by waste disposal wells in the Florida keys, Water Research, Volume 31, Issue 6, p.1448-1454, 1997.

Raupach, M.R., G. Marland, P. Ciais, P., C. Le Quéré, J.G. Canadell, G. Klepper, and C.B. Field, Global and regional drivers of accelerating $\mathrm{CO}_{2}$ emissions, Proceedings of the National Academy of Sciences, 104(24), 10288-10293, 2007.

Rish, W.R., A probabilistic risk assessment of Class I hazardous waste injection sites, in Tsang, C.F., and J.A. Apps (eds.), Underground Injection Science and Technology, Developments in Water Science, 52, 93-125, 2005.

RRC (Railroad Commission of Texas), Hearing file Oil and Gas Docket Nos. 3-96,354 and 3-97,061: The application of Western Gas Resources Storage Inc. for Commission authority to operate the Fulshear (Hillebrenner) field as a natural gas storage facility and for authority to inject dry gas into the Fulshear (Hillebrenner) field, Fort Bend County, Texas, 1991.

RRC Well Database, http://www.rrc.state.tx.us/other-information/automated/itssmap.html, acquired 2005.

Savage, D., P.R. Maul, S. Benbow, and R.C. Walke, A generic FEP database for the assessment of long-term performance and safety of the geological storage of $\mathrm{CO}_{2}$, Quintessa Report QRS1060A-1, 73 pp., 2004.

Smith, F. L., Jr., and J. T. Goodwyn, Jr., Fulshear and Finfrock Fields-Fort Bend and Harris Counties, Texas, in Typical Oil and Gas Fields of Southeast Texas, Houston Geological Society, p. 68-73, 1962.

Stauffer, P.H., H.S. Viswanathan, R.J. Pawar, and G.D. Guthrie, A system model for geologic sequestration of carbon dioxide, Environmental Science and Technology, 43(3), 565-570, 2009.

Stenhouse, M., W. Zhou, D. Savage, and S. Benbow, Framework methodology for long-term assessment of the fate of $\mathrm{CO}_{2}$ in the Weyburn field, in Thomas, D.C., and Benson, S.M., eds., Carbon dioxide capture for storage in deep geologic formations-results from the Carbon Capture Project, vol. 2, 1251-1261, Elsevier, 2005.

TCEQ (Texas Commission on Environmental Quality), Texas Water Utility Database (iWUD), http://www3.tceq.state.tx.us/iwud/ , City of Katy Public Water Supply (PWS) \# 1010017, 2007. 
TWDB (Texas Water Development Board), 2002, http://www.twdb.state.tx.us/gam/resources/resources.htm , file GAMPredictivePumpage_2002SWP.zip, last accessed June 28, 2008.

Thorkildsen, D., Evaluation of Water Resources of Fort Bend County, Texas: Texas Water Development Board Report 321, 21 p., 1990.

USEPA, Technical Program Overview, Underground injection control regulations, Office of Water 4606, EPA 816-R-02-025, Revised July 2001. http://www.epa.gov/safewater/uic/index.html

USEPA, Inventory of U.S. greenhouse gas emissions and sinks: 1990-2006, EPA 430-R-07-002, 458 p., 2007, (http://www.epa.gov/climatechange/emissions/downloads/08_ES.pdf)

USEPA, Geologic Sequestration Vulnerability Evaluation Framework, Office of Air and Radiation, in preparation, 2008.

Veil, J., Testimony of John A. Veil, Argonne National Laboratory before the House Committee on Science and Technology Subcommittee on Energy and the Environment, October 30, 2007 (http://www.ead.anl.gov/pub/doc/testimony_veil_final.pdf)

Wildenborg, T., T. Leijnse, E. Kreft, M. Nepveu, and A. Obdam, Long term safety assessment of $\mathrm{CO}_{2}$ storage: The scenario approach, in Seventh International Conference on Greenhouse Gas Control Technologies (GHGT-7), Sept. 7-11, 2004.

Wilson, E.J., T.L. Johnson, and D.W. Keith, Regulating the ultimate sink: Managing the risks of geologic CO2 storage, Environ. Sci. Technol., 37, 3476-3483, 2003.

Woodruff, C. M., C. Gever, and W. D. Wuerch, Geothermal Gradient Map of Texas: The University of Texas at Austin, Bureau of Economic Geology, scale 1:1,000,000, 1984. 


\section{List of Acronyms}

$\begin{array}{ll}\text { CF } & \text { Certification Framework } \\ \text { CLR } & \text { CO }_{2} \text { Leakage Risk } \\ \text { CMG-GEM } & \text { Computer Modeling Group - Generalized Equation-of-State Model } \\ \text { DOE } & \text { U.S. Department of Energy } \\ \text { ECA } & \text { Emissions Credit and Atmosphere } \\ \text { EPA } & \text { Environmental Protection Agency } \\ \text { FEP } & \text { Features, Events, and Processes } \\ \text { GCS } & \text { Geologic carbon sequestration } \\ \text { GEM } & \text { Generalized Equation-of-State Model } \\ \text { gPm } & \text { gallon per minute } \\ \text { HMR } & \text { Hydrocarbon and Mineral Resources } \\ \text { HS } & \text { Health and Safety } \\ \text { MGD } & \text { million gallons a day } \\ \text { mpg } & \text { miles per gallon } \\ \text { Mt } & \text { Million tonnes (10 } 9 \text { kg) } \\ \text { NEE } & \text { Net Ecosystem Exchange } \\ \text { NSE } & \text { Near Surface Environment } \\ \text { RRC } & \text { Railroad Commission of Texas } \\ \text { SGR } & \text { Shale Gouge Ratio } \\ \text { TDS } & \text { Total Dissolved Solids } \\ \text { UIC } & \text { Underground Injection Control program of the US EPA } \\ \text { US (U.S.) } & \text { United States } \\ \text { USDW } & \text { Underground Source of Drinking Water } \\ & \end{array}$




\section{Tables}

Table 1. Comparison of U.S. fluids injected and $\mathrm{CO}_{2}$ emissions.

\begin{tabular}{|c|c|c|c|}
\hline & $\begin{array}{l}\text { U.S. Water } \\
\text { Injection }\end{array}$ & Class $1 \mathrm{H}^{>>}$ & $\begin{array}{l}\text { U.S. power } \\
\text { generation } \mathrm{CO}_{2} \\
\text { emissions }\end{array}$ \\
\hline Mass & $3 \mathrm{Gt} \mathrm{H}_{2} \mathrm{O} / \mathrm{yr}^{*}$ & $33 \mathrm{Mt} \mathrm{H}_{2} \mathrm{O} / \mathrm{yr}^{\dagger}$ & $2.4 \mathrm{Gt} \mathrm{CO}_{2} / \mathrm{yr}^{\ddagger}$ \\
\hline Volume** & $\begin{array}{l}3 \mathrm{Gm}^{3} \mathrm{H}_{2} \mathrm{O} / \mathrm{yr} \\
\left(20 \mathrm{Gbbl} \mathrm{H}_{2} \mathrm{O} / \mathrm{yr}\right)\end{array}$ & $\begin{array}{l}33 \mathrm{Mm}^{3} \mathrm{H}_{2} \mathrm{O} / \mathrm{yr} \\
\left(220 \mathrm{Mbbl} \mathrm{H}_{2} \mathrm{O} / \mathrm{yr}\right)\end{array}$ & $\begin{array}{l}3.4 \mathrm{Gm}^{3} \mathrm{CO}_{2} / \mathrm{yr} \\
\left(22 \mathrm{Gbbl} \mathrm{CO}_{2} / \mathrm{yr}\right)\end{array}$ \\
\hline $\begin{array}{l}\text { Volume ratio } \\
\text { relative to } \mathrm{CO}_{2}\end{array}$ & 0.9 & 0.01 & 1.0 \\
\hline Significance & $\begin{array}{l}\text { Mostly replaces } \\
\text { produced water } \\
\text { and oil }\end{array}$ & $\begin{array}{l}1 / 100 \text { the volume of } \\
\text { potential } \mathrm{CO}_{2} \\
\text { injection }\end{array}$ & $\begin{array}{l}\text { Displaces existing } \\
\text { fluid, buoyant } \\
\text { relative to existing } \\
\text { fluid }\end{array}$ \\
\hline
\end{tabular}

$\mathrm{G}=10^{9}, \mathrm{M}=10^{6}, \mathrm{t}=10^{3} \mathrm{~kg}, \mathrm{bbl}=$ barrel $=42 \mathrm{gal}=0.16 \mathrm{~m}^{3}$

${ }^{*}$ Veil, 2007; ${ }^{\dagger}$ Benson et al., 2002; ${ }^{\ddagger}$ USEPA, 2007

**reservoir conditions assuming $\rho \mathrm{CO}_{2}=700 \mathrm{~kg} / \mathrm{m}^{3}$

>> $\mathrm{H}=$ Hazardous 
Table 2. Flow characteristics of a vertical profile in the vicinity of Fulshear site. All interval and thickness values rounded to the closest $5 \mathrm{~m}$ or $10 \mathrm{ft}$.

\begin{tabular}{|c|c|c|c|c|c|}
\hline $\begin{array}{l}\text { Interval } \\
\text { in } \mathrm{m} \text { amsl } \\
(\mathrm{ft} \text { amsl) }\end{array}$ & $\begin{array}{l}\text { Thickness } \\
\text { in m (ft) }\end{array}$ & Formations & $\begin{array}{l}\text { Permeable } \\
\text { or Sealing }\end{array}$ & Comments & Reference \\
\hline $\begin{array}{l}40 \text { to } \\
-140 \\
(130 \text { to } \\
-450)\end{array}$ & $180(580)$ & $\begin{array}{l}\text { Willis, etc. } \\
\sim \text { Chicot aquifer }\end{array}$ & Permeable & $\begin{array}{l}\text { Cumulative sand } \\
\text { thickness of } \sim 300 \mathrm{ft} \\
\text { ( } 55 \% \text { sand percentage); } \\
\text { permeability is 18,500 } \\
\text { md. }\end{array}$ & \\
\hline $\begin{array}{l}-140 \text { to } \\
-580 \\
(-450 \text { to } \\
-1900) \\
\end{array}$ & $440(1450)$ & $\begin{array}{l}\text { Goliad } \\
\sim \text { Evangeline } \\
\text { aquifer }\end{array}$ & Permeable & $\begin{array}{l}\text { Cumulative sand } \\
\text { thickness of } \sim 800 \mathrm{ft} \\
\text { (55\% sand percentage); } \\
\text { permeability is } 3700 \mathrm{md} \text {. }\end{array}$ & $\begin{array}{l}\text { Kasmarek } \\
\text { and } \\
\text { Robinson, } \\
2004\end{array}$ \\
\hline $\begin{array}{l}-580 \text { to } \\
-700 \\
(-1900 \text { to } \\
-2300)\end{array}$ & $120(400)$ & $\begin{array}{l}\text { Upper Fleming } \\
\sim \text { Burkeville } \\
\text { confining unit }\end{array}$ & Sealing & Claystone & $\begin{array}{l}\text { Kasmarek } \\
\text { and } \\
\text { Robinson, } \\
2004\end{array}$ \\
\hline $\begin{array}{c}-700 \text { to } \\
-990 \\
(-2300 \text { to } \\
-3250) \\
\end{array}$ & $290(950)$ & $\begin{array}{l}\text { Fleming/Oakvill } \\
\text { e Sands } \sim \text { Jasper } \\
\text { aquifer }\end{array}$ & Permeable & $\begin{array}{l}\text { Cumulative sand } \\
\text { thickness of } \sim 300 \mathrm{ft} \\
\text { (32\% sand percentage); } \\
\text { permeability is } 2960 \mathrm{md} \text {. }\end{array}$ & $\begin{array}{l}\text { Kasmarek } \\
\text { and } \\
\text { Robinson, } \\
2004 \\
\end{array}$ \\
\hline $\begin{array}{c}-990 \text { to } \\
-1015 \\
(-3250 \text { to } \\
-3330)\end{array}$ & $25(80)$ & Anahuac & Sealing & Claystone & $\begin{array}{l}\text { Galloway et } \\
\text { al., } 1986\end{array}$ \\
\hline $\begin{array}{l}-1015 \text { to } \\
-1515 \\
(-3330 \text { to } \\
-4980)\end{array}$ & $500(1650)$ & Catahoula/Frio & $\begin{array}{c}\text { Permeable } \\
\text { and Sealing }\end{array}$ & $\begin{array}{l}\text { Mostly claystone but } \\
\text { includes seven } \sim 50 \text {-ft } \\
\text { thick sand intervals (that } \\
\text { is, a sand percentage of } \\
14 \% \text {; porosity is } 30 \% \\
\text { and permeability is } 400 \\
\text { md. }\end{array}$ & $\begin{array}{l}\text { Bebout et al., } \\
1976\end{array}$ \\
\hline $\begin{array}{l}-1515 \text { to } \\
-1610 \\
(-4980 \text { to } \\
-5280)\end{array}$ & 95 (300) & Vicksburg & Sealing & Claystone & $\begin{array}{l}\text { Combes, } \\
1993\end{array}$ \\
\hline $\begin{array}{l}-1610 \text { to } \\
-1675 \\
(-5280 \text { to } \\
-5500)\end{array}$ & $65(220)$ & $\begin{array}{l}\text { Lower } \\
\text { Vicksburg }\end{array}$ & Permeable & $\begin{array}{l}\text { Three } 40 \text {-ft thick sand } \\
\text { intervals, } 2 \text { intermediate } \\
25-\mathrm{ft} \text { thick claystone } \\
\text { intervals, and a basal } 50 \text { - } \\
\mathrm{ft} \text { thick claystone } \\
\text { interval. Porosity is } \\
23.4 \% \text { and permeability } \\
\text { is } 40 \mathrm{md} \text {. }\end{array}$ & $\begin{array}{l}\text { Combes, } \\
1993\end{array}$ \\
\hline $\begin{array}{l}-1675 \text { to } \\
-2025 \\
(-5500 \text { to } \\
-6650)\end{array}$ & $350(1150)$ & Jackson & Sealing & Mostly claystone & $\begin{array}{l}\text { Fisher et al., } \\
1970\end{array}$ \\
\hline $\begin{array}{l}-2025 \text { to } \\
-2130 \\
(-6650 \text { to } \\
-7000)\end{array}$ & $105(350)$ & $\begin{array}{l}\text { Top of Yegua } \\
\text { above } \\
\text { Hillebrenner } \\
\text { Sand }\end{array}$ & Sealing & Claystone & Fisher, 1969; \\
\hline
\end{tabular}


Table 3. Properties used in the Fulshear reservoir simulation.

\begin{tabular}{|l|c|c|}
\hline \multicolumn{1}{|c|}{ Property } & Value & $\begin{array}{c}\text { Value } \\
\text { (metric units) }\end{array}$ \\
\hline \hline Porosity & 0.25 & \\
\hline Permeability & $136 \mathrm{md}$ & $1.36 \times 10^{-13} \mathrm{~m}^{2}$ \\
\hline Residual liquid saturation & 0.25 & 0.25 \\
\hline Residual gas saturation & 0.25 & 0.25 \\
\hline Capillary pressure maximum & $0.0 \mathrm{psi}$ & $0.0 \mathrm{MPa}$ \\
\hline Thickness & $50 \mathrm{ft}$ & $15 \mathrm{~m}$ \\
\hline $\mathrm{k}_{\mathrm{V}} / \mathrm{k}_{\mathrm{h}}$ & 0.04 & 0.04 \\
\hline Dip & $1^{\circ}$ & $1^{\circ}$ \\
\hline Depth & $6750 \mathrm{ft}$ & $2057 \mathrm{~m}$ \\
\hline Temperature & $140^{\circ} \mathrm{F}$ & $60{ }^{\circ} \mathrm{C}$ \\
\hline Well type & Vertical & Vertical \\
\hline Injection Rate & $0.8 \mathrm{Mt} / \mathrm{yr}$ & $0.8 \mathrm{Mt} / \mathrm{yr}$ \\
\hline Perforation Interval & Fully & Fully perforated \\
& perforated & \\
\hline Period of Injection & 30 yrs & 30 yrs \\
\hline
\end{tabular}


Figures
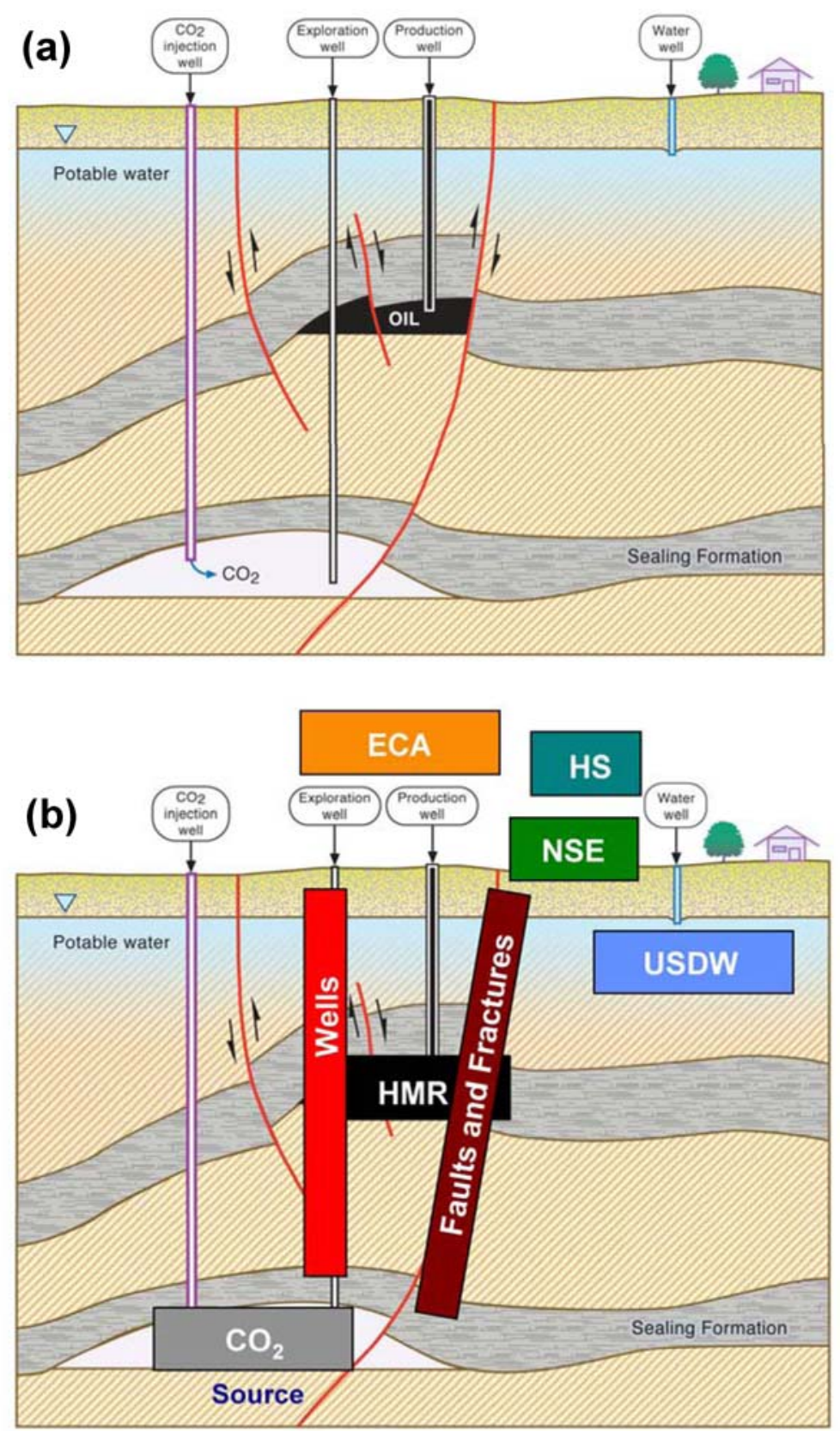

Figure 1. (a) Generic geologic cross section of potential GCS site showing reservoir and sealing formations, faults, wells, USDW, and near-surface and surface environments. (b) Generic cross section with CF source and compartments overlaid. 


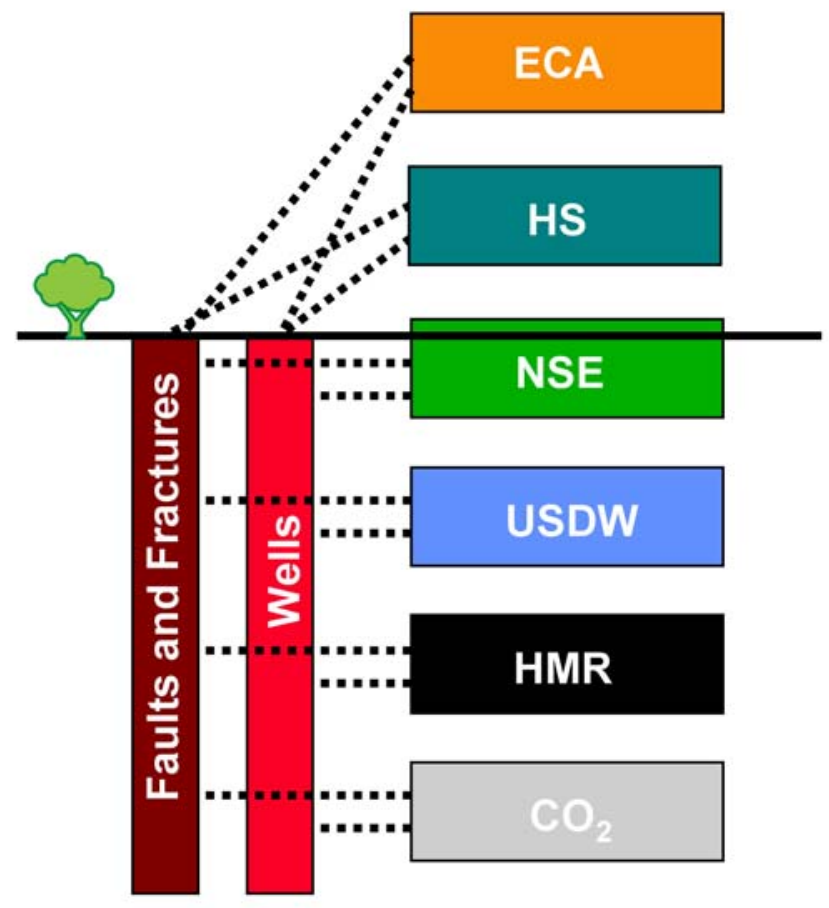

Figure 2. CF conduits, source, and five compartments with dotted connection lines indicating potential but not certain intersection. 


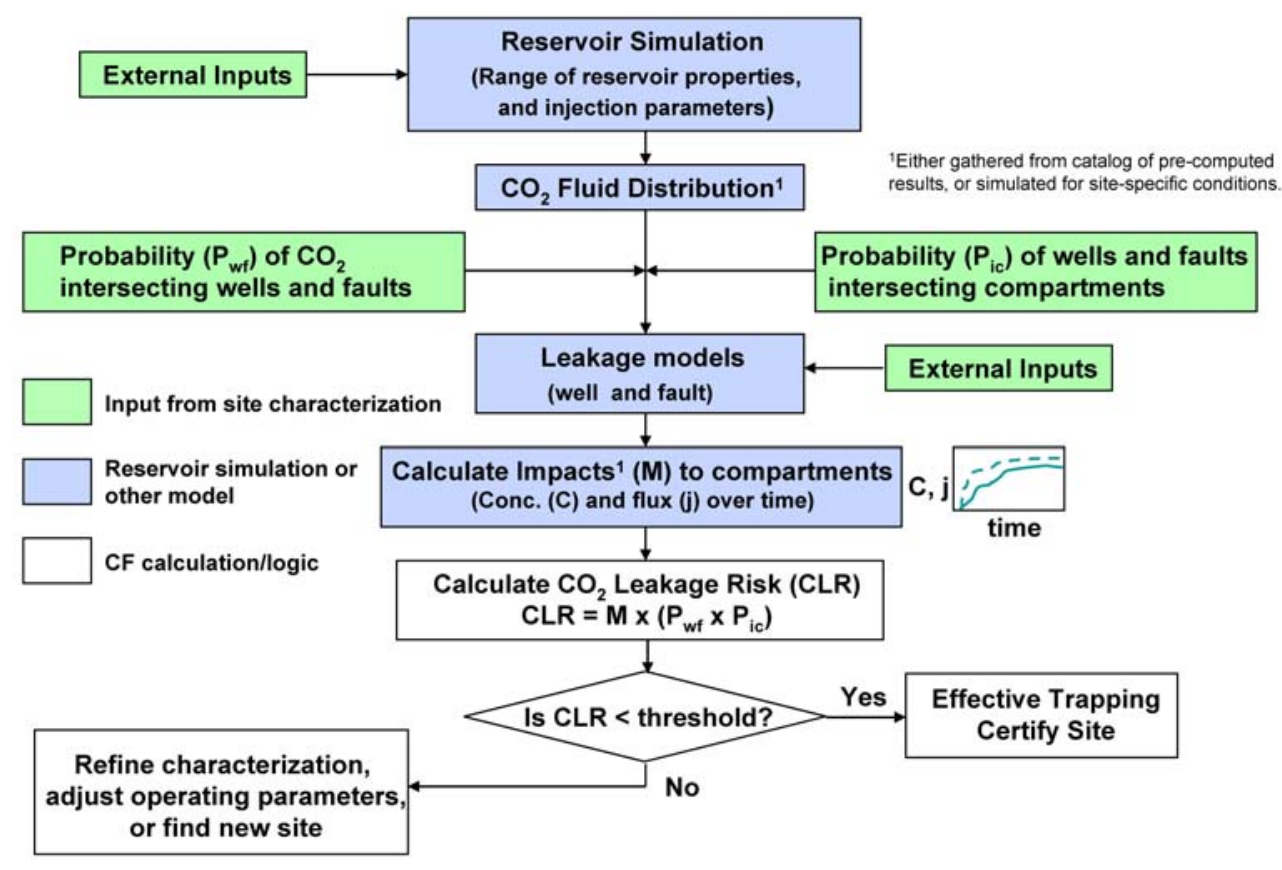

Figure 3. Flow chart of CF-CLR process showing logic and inputs and outputs. 


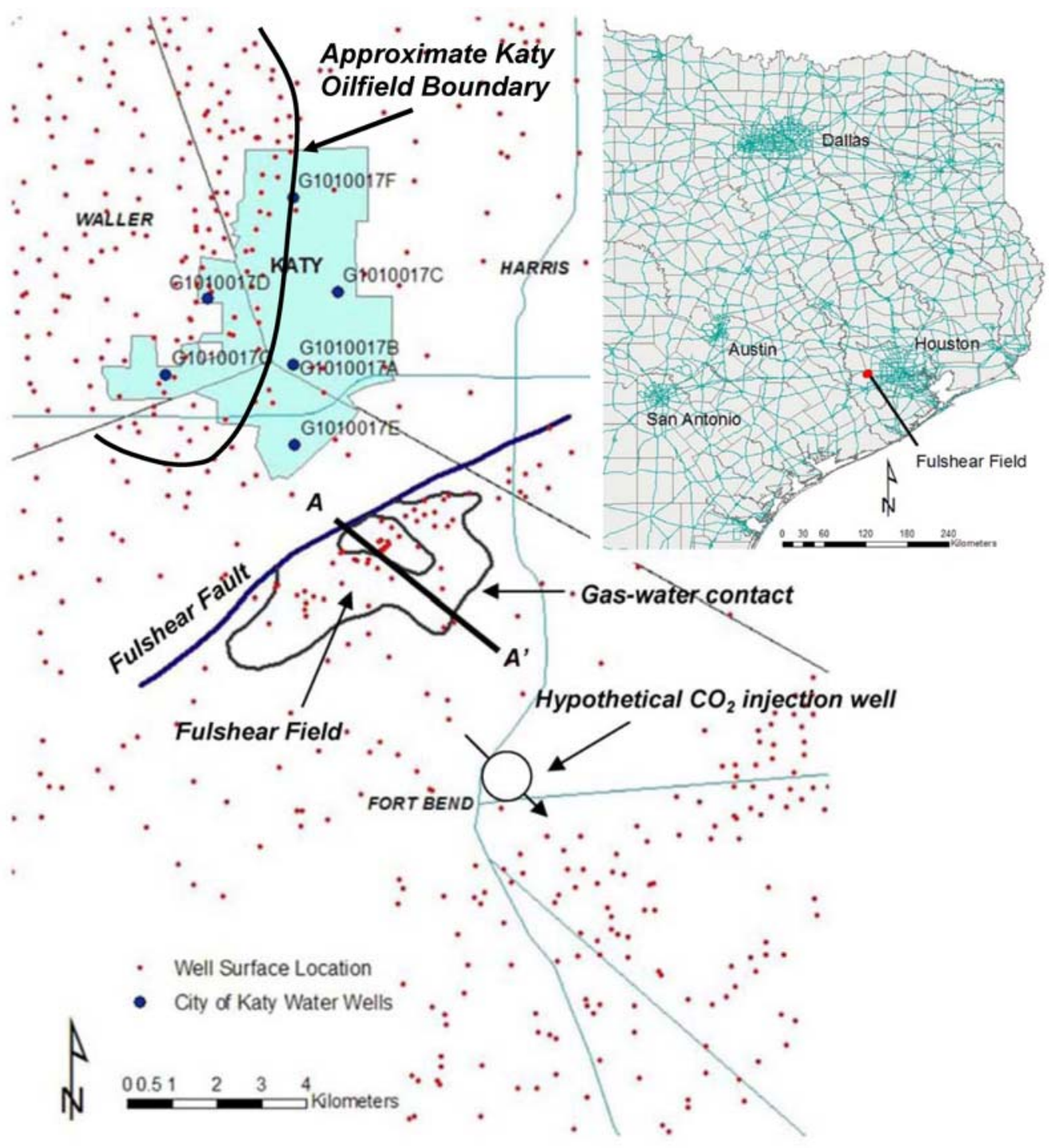

Figure 4. Location map of a hypothetical GCS project in the Texas Gulf Coast showing oil and gas wells (small red dots), water wells, Fulshear gas reservoir, and injection well in the water leg of the Hillebrenner Sand. County names and limits are also displayed as well as cross-section location. 


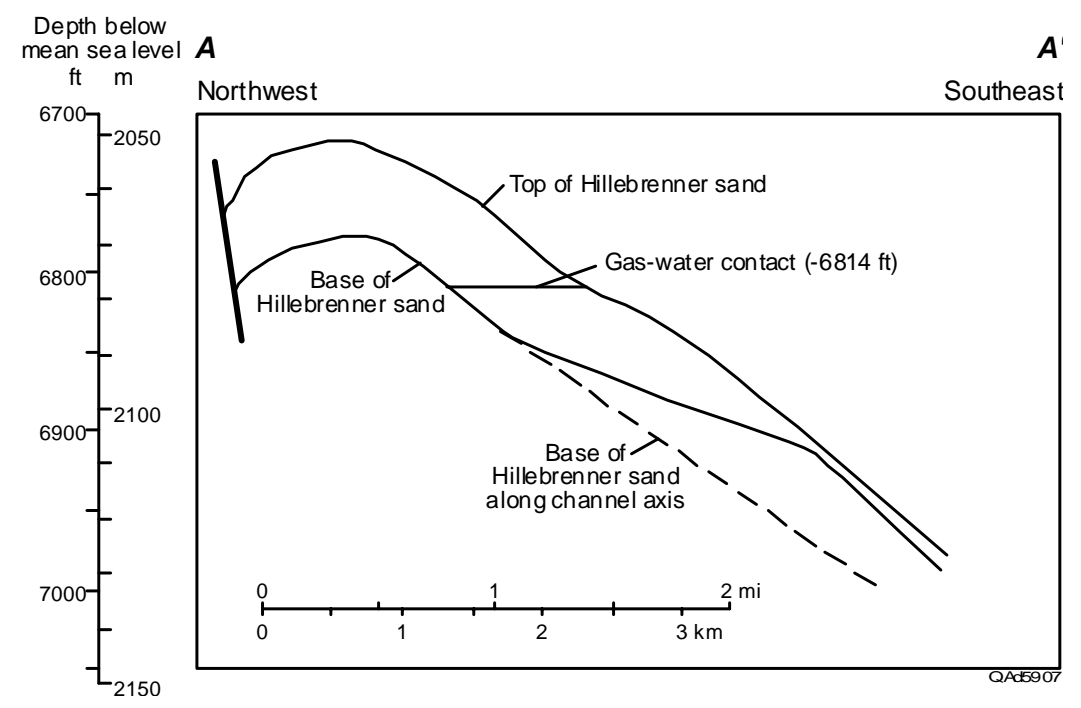

Figure 5. Cross section through the Fulshear gas reservoir showing growth fault, gas cap, and downdip water leg. Note vertical exaggeration; dip of the Hillebrenner is approximately $1^{\circ}$ to the southeast. Cross-section location is shown in Figure 4. 


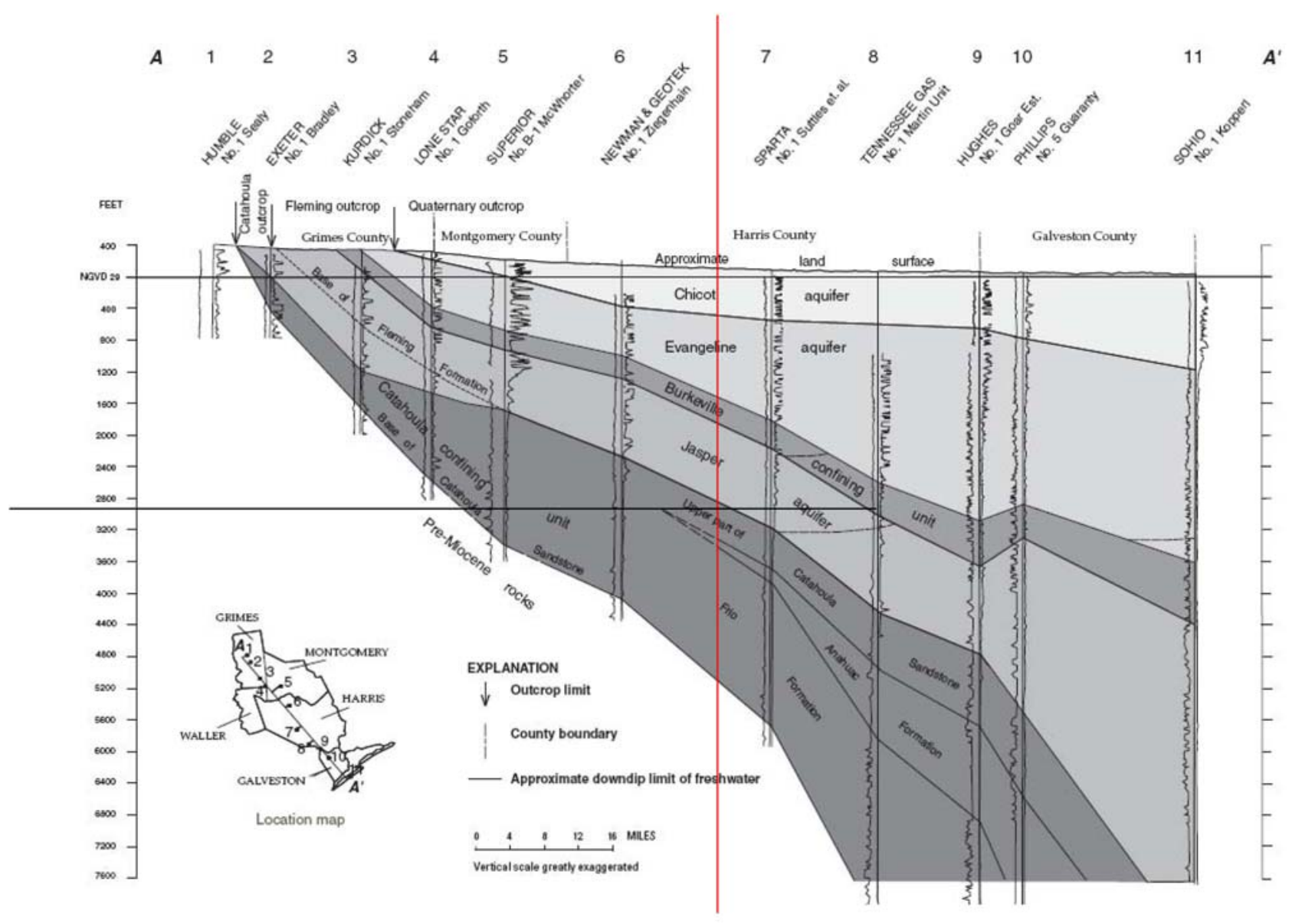

Figure 6. Cross section showing aquifers above the Fulshear reservoir. Long vertical (red) line is location of hypothetical $\mathrm{CO}_{2}$ injection well; injection interval is at approximately $7000 \mathrm{ft}$ depth (source: Baker, 1986). 
(a)

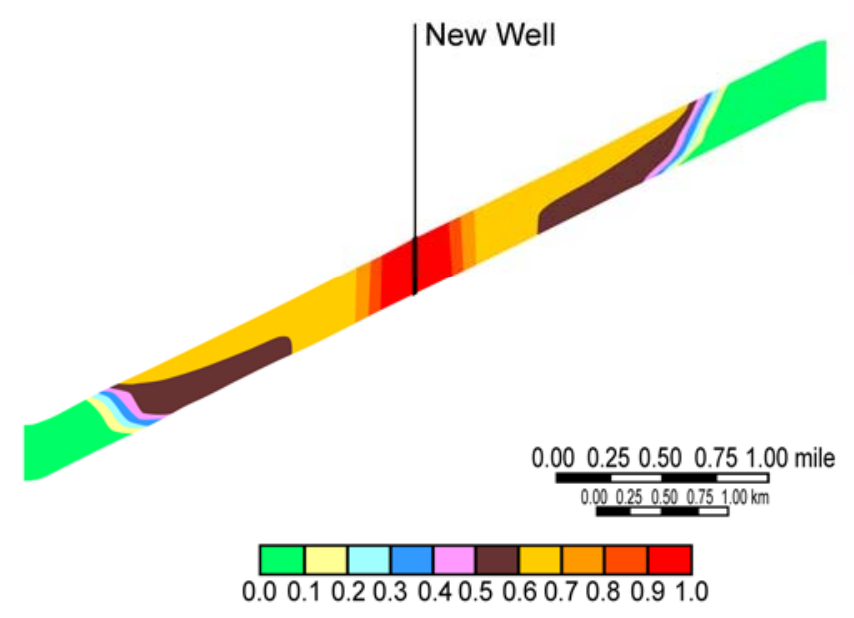

(c)

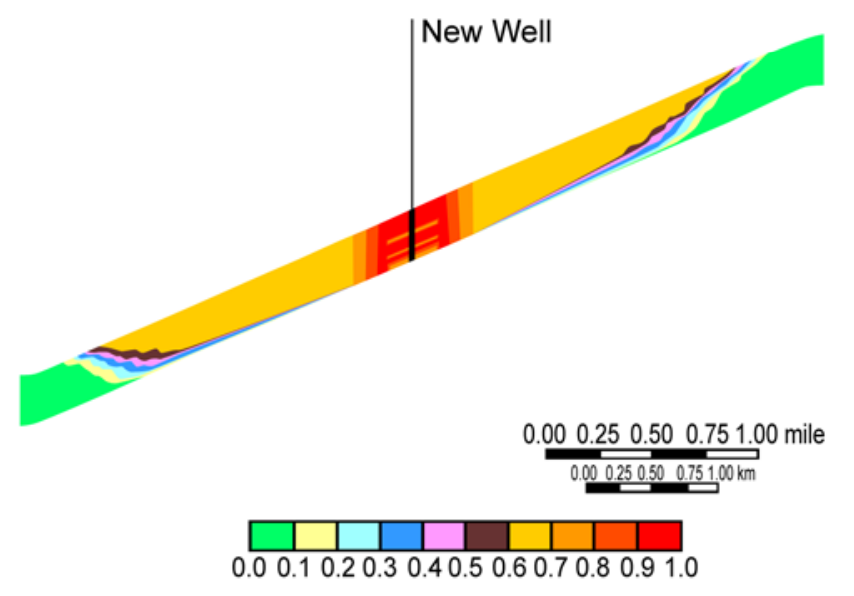

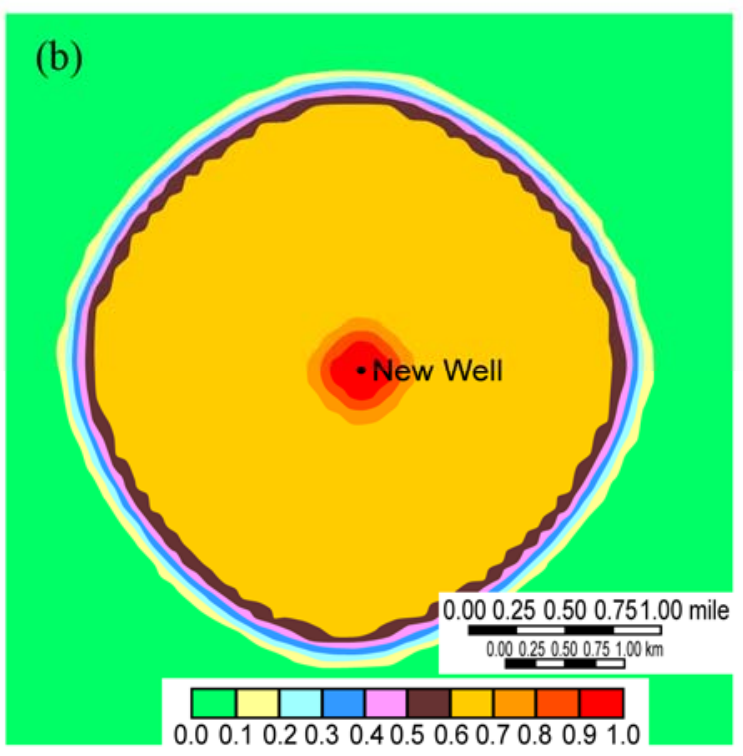

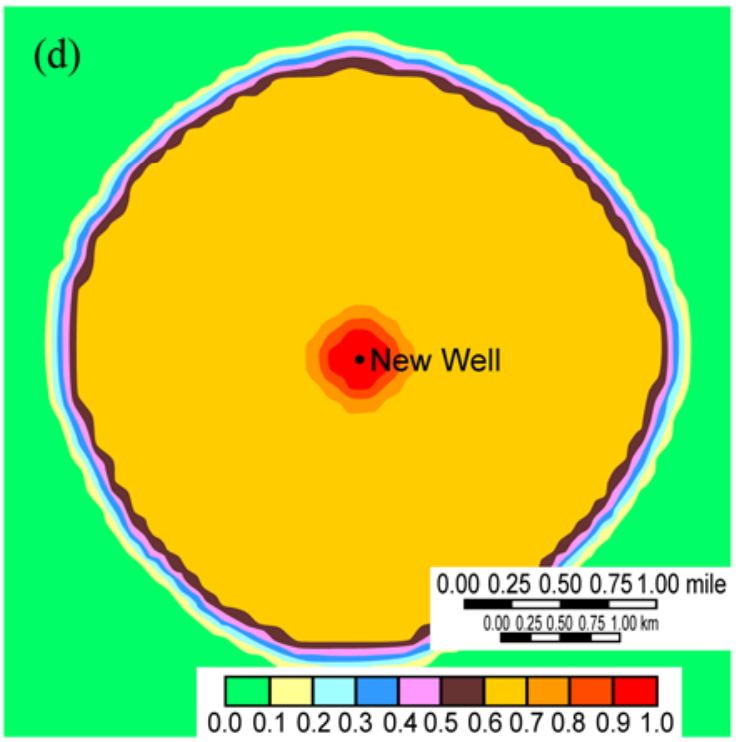

Figure 7. Plume extent shown by gas saturation in vertical cross sections and plan view after $30 \mathrm{yrs}$ of injection ( $a$ and $b$ ) and after 70 years of shut-in (c and d). Note vertical exaggeration in cross sections-dip is actually $1^{\circ}$. 


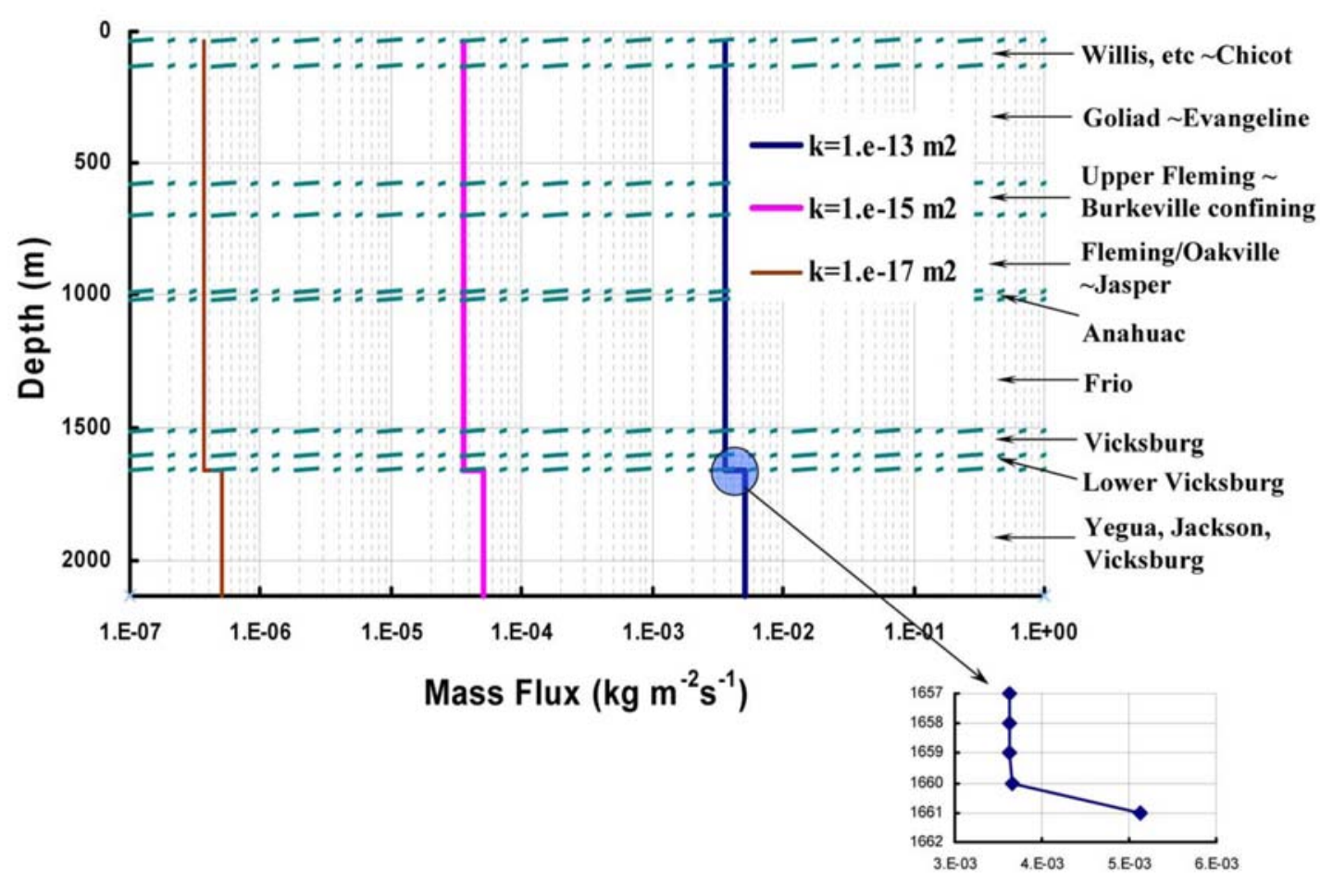

Figure 8. Modeled mass flux of $\mathrm{CO}_{2}$ leaking up abandoned wells with three different effective permeabilities. 